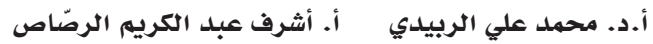

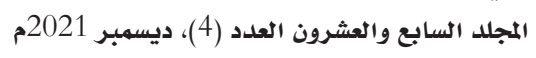

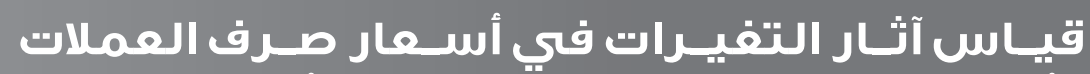

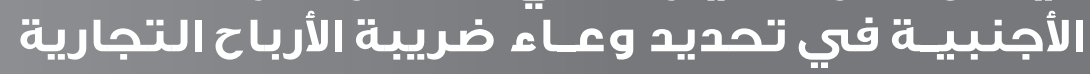

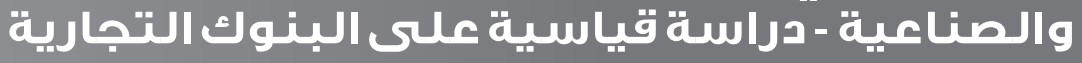

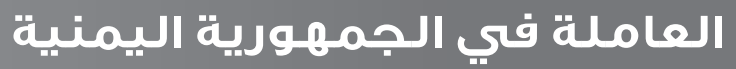

الاســتلام : 10 / التحكيــيو / 2021

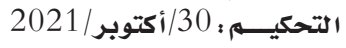

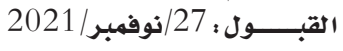

أ.د. مححمد علي الربيلي) (1،)

أ. أشرف عبل الكريم الرصّاص 2

(C) 2021 University of Science and Technology, Yemen. This article can be distributed under the terms of the Creative Commons Attribution License, which permits unrestricted use, distribution, and reproduction in any medium, provided the original author and source are credited.

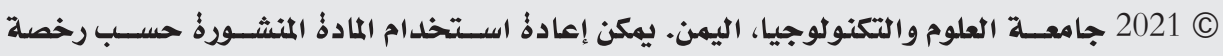
مؤسسة المشاع الإبداعي شريطة الاستشهاد بالمؤلف والمجلة المئلة المادئ. 
قياس آثار التغيرات في أسعار صرف العملات الأجنبية في تحديد وعاء

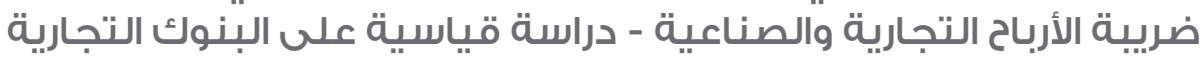
العاملة في الجمهورية - درالمة قيالية اليمنية

الملخص:

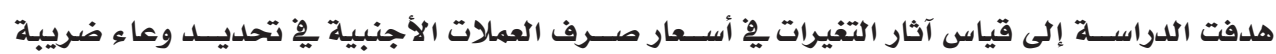

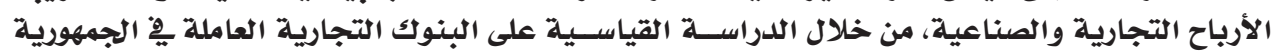

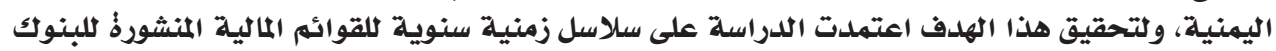

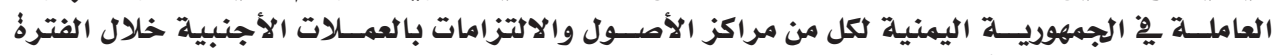

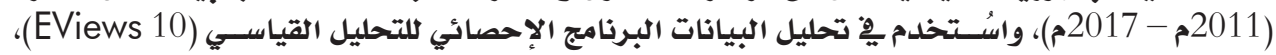

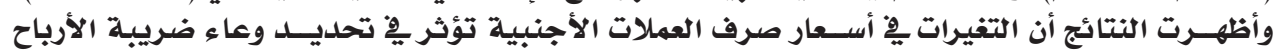

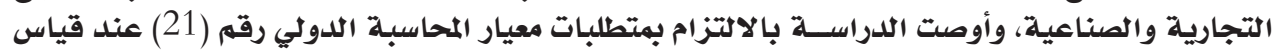

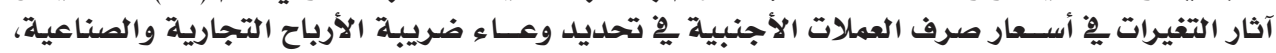

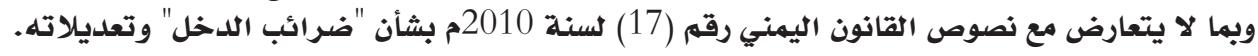
الكلمات المفتاحية : القياس المحاسـبي، التغيرات فِ أسعار صرف العملات الأجنبية، وعاء ضريبة الأرباح التجارية والصناعية. المفتاحية. 


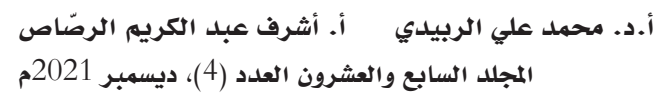

\title{
Measuring the Effects of Changes in Foreign Exchange Rates on Determining the Commercial and Industrial Profits Tax Base: A Standard Study on Commercial Banks Operating in the Republic of Yemen
}

\begin{abstract}
:
The study aimed to measure the effects of changes in foreign exchange rates on determining the commercial and industrial profits tax base, through a standard study on commercial banks operating in the Republic of Yemen. To achieve this goal, the study relied on annual time series of the published financial statements of banks operating in the Republic of Yemen for each of the foreign currency position of assets and liabilities during the period (2011-2017). The Statistical Analysis Software (EViews V.10) was used in data analysis. The results showed that changes in foreign exchange rates affect the determination of the commercial and industrial profits tax base. The study recommends adherence to the requirements of International Accounting Standard No. (21) when measuring the effects of changes in foreign exchange rates on determining the commercial and industrial profits tax base, in a manner that does not conflict with the provisions of Yemeni Law No. (17) of 2010 "income taxes" and its amendments.
\end{abstract}

Keywords: accounting measurement, changes in foreign exchange rates, commercial and industrial profit tax base. 


\section{المقدمة:}

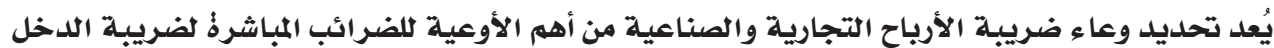

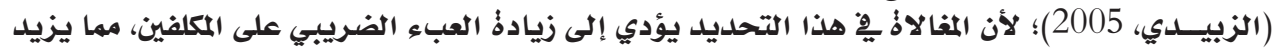

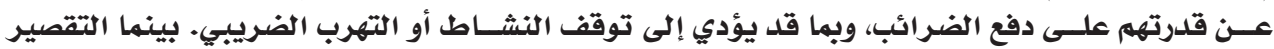

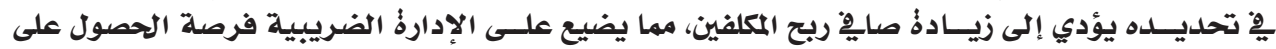

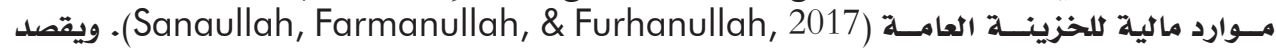

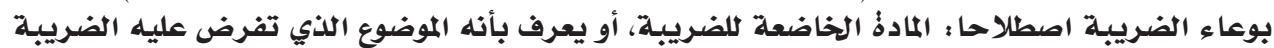
(الزبيدي، 2005؛ حسين ويعقوب، 2013).

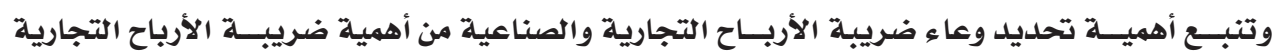

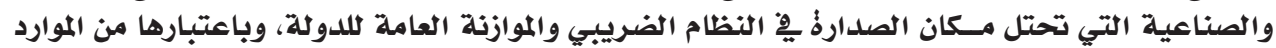

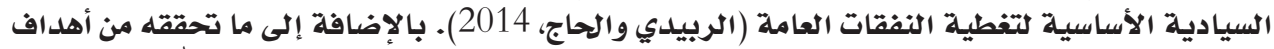

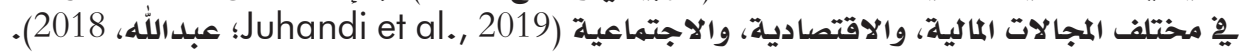

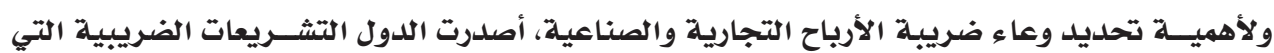

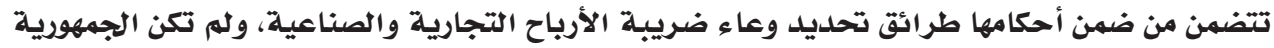

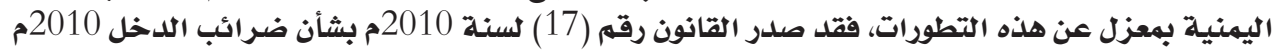

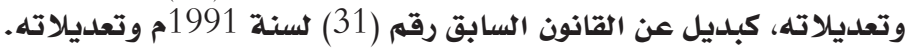

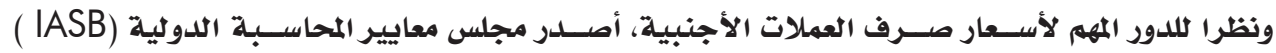

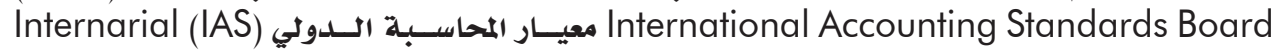
Accounting Standard

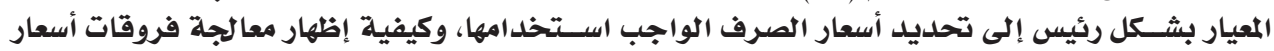

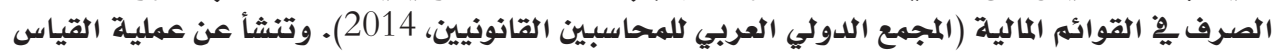

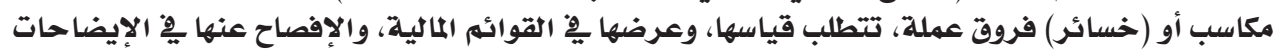
المتهمة للقوائم المالية.

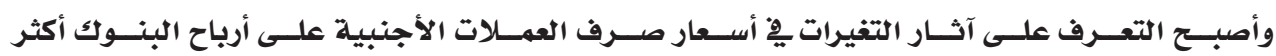

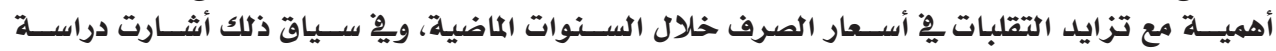
والأيّ

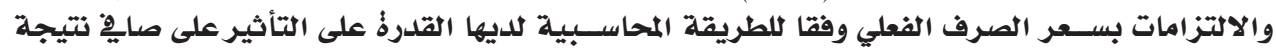

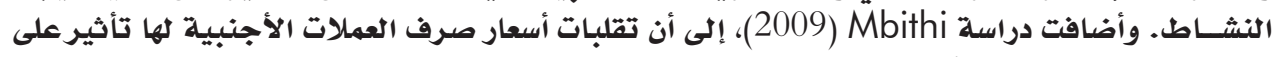

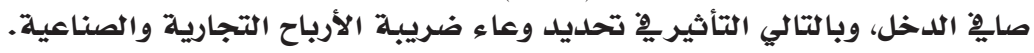

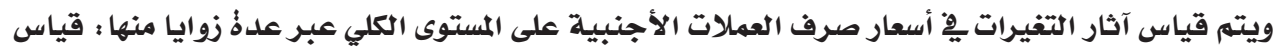

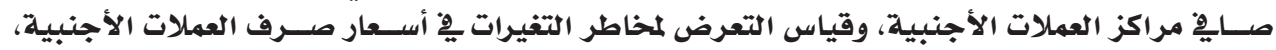

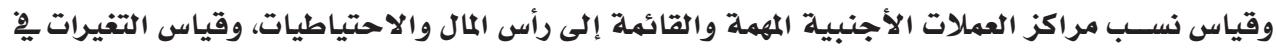
القيمة العادلة للمعاملات بالعملة الأجنبية (تحليل الحساسية للتعاملات بالعالعماتلة العملة الأجنبية).

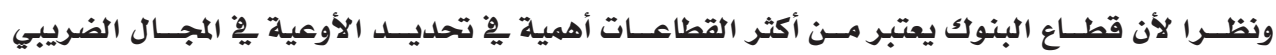

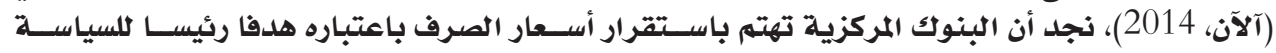

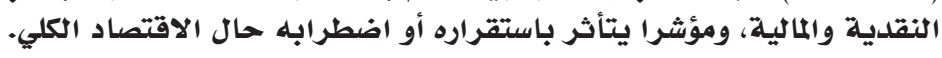




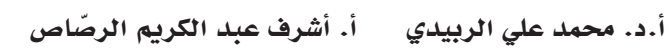

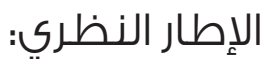

القياس المحاسبي لآثار التغيرات يِّ أسعار صرف العملات الأجنبية ؛

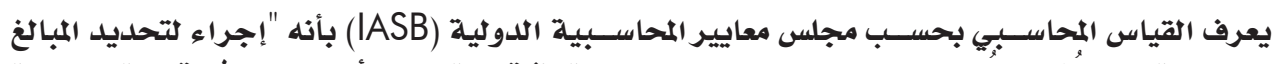

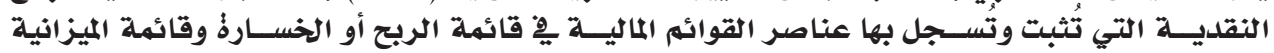

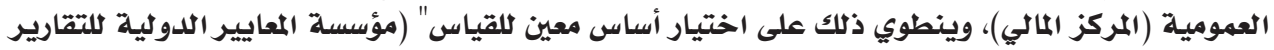

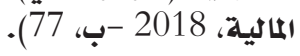

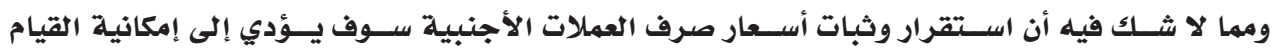

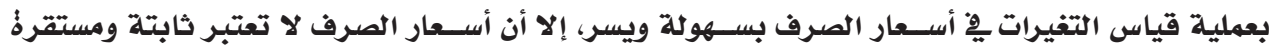

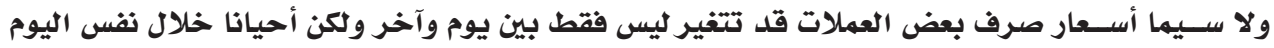

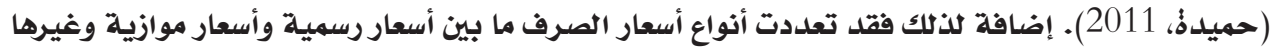

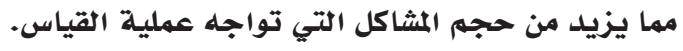

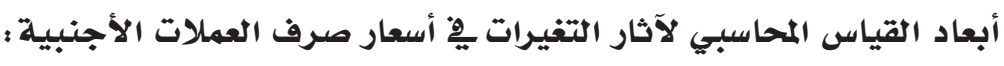

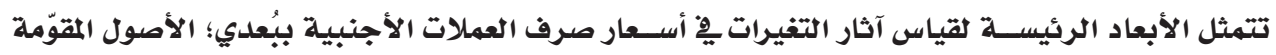

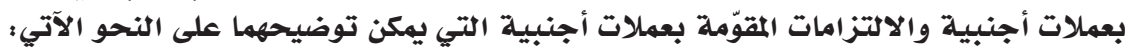

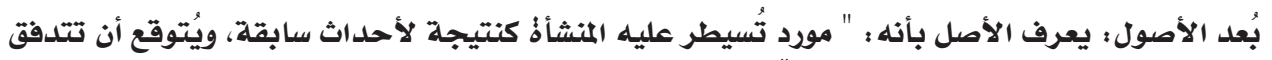

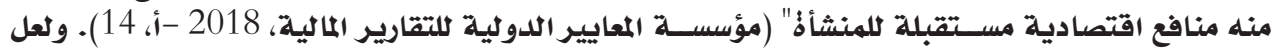

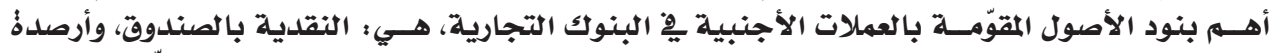

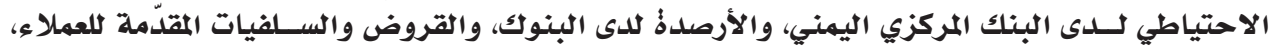

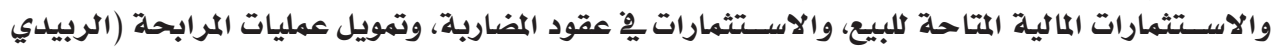
وبا مشموس، 2008).

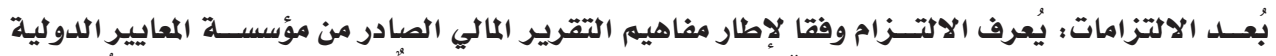

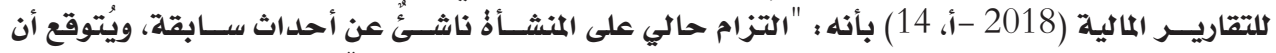

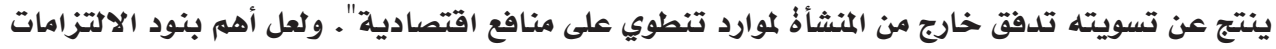

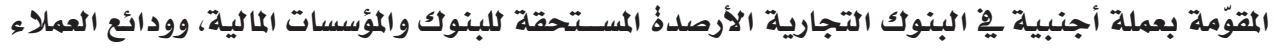
(الربيدي وبامشموس، 2008).

مؤشرات القياس المحاسبي لآثار التغيرات ِِّ أسعار صرف العملات الأجنبية ؛

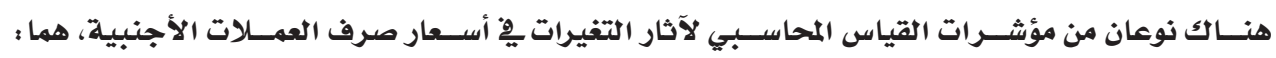

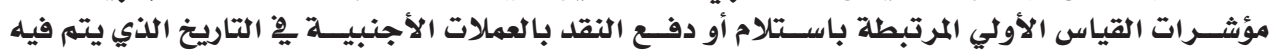

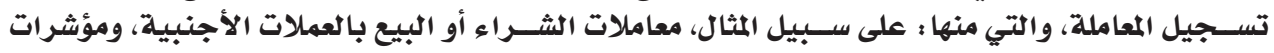

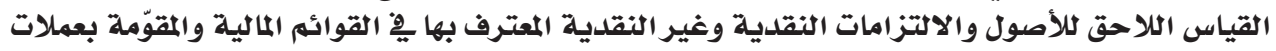

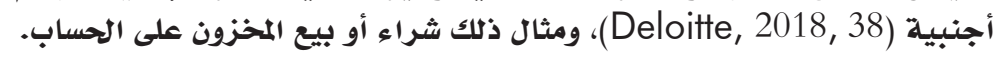
مؤشرات القياس الأولي لآثار التغيرات يـ أسعار صرف العملات الأجنبية :

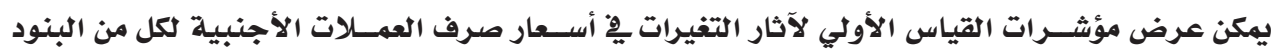

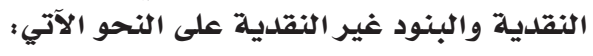

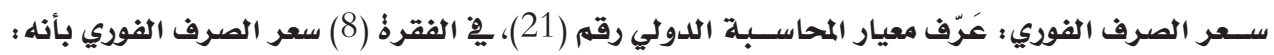

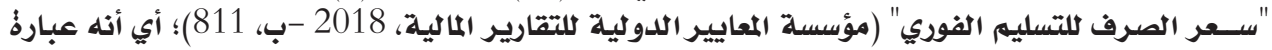

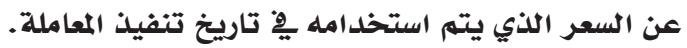


مؤشرات القياس الكلاحق ثآثار التغيرات ِِّ أسعار صرف العملات الأجنبية ؛

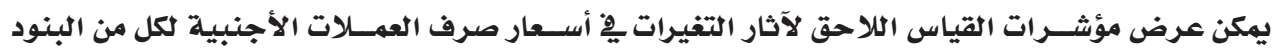

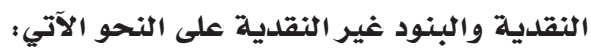

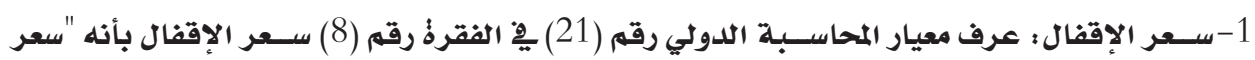

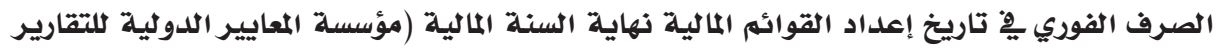

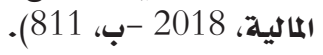

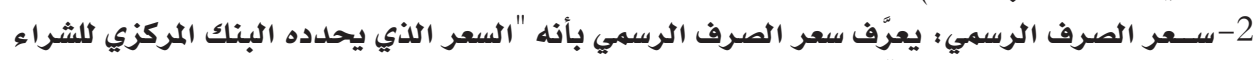

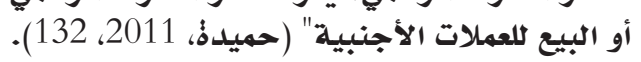

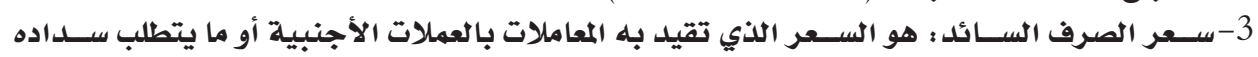

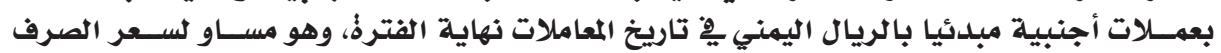

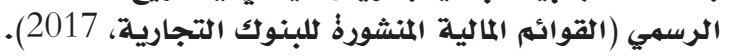

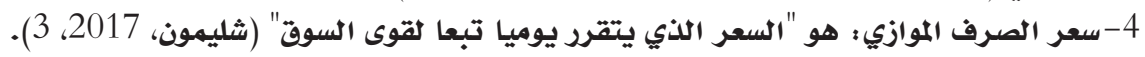

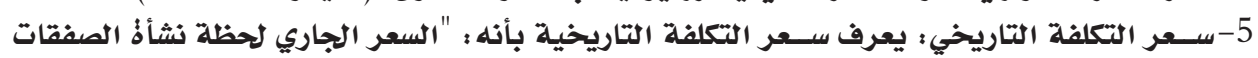

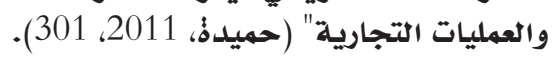

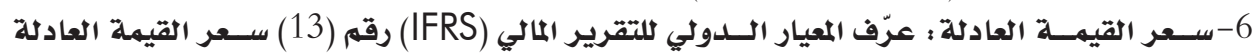

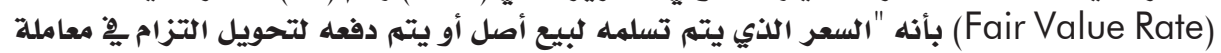

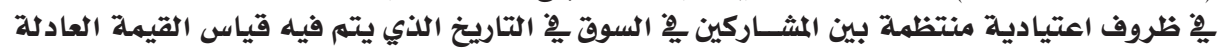

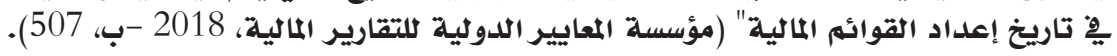
قياس آثار التغيرات ٍِِ أسعار صرف العملات الأجنبية لصايِّ مراكز العملات الأجنبية ؛

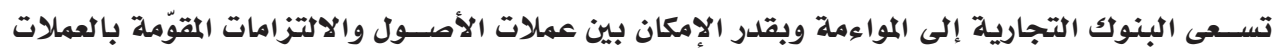

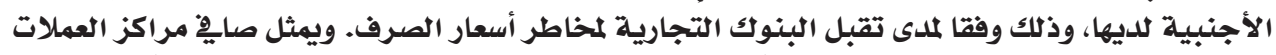

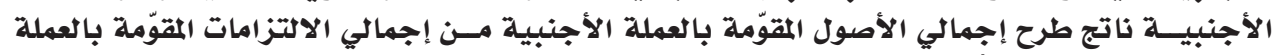

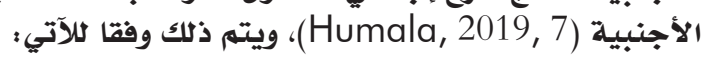

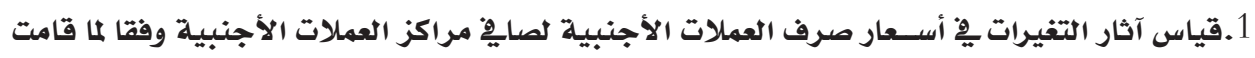

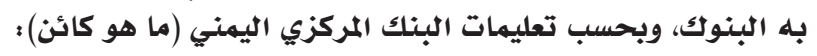

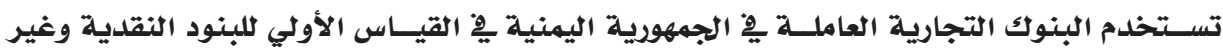

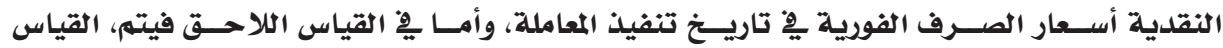

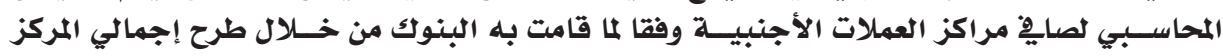

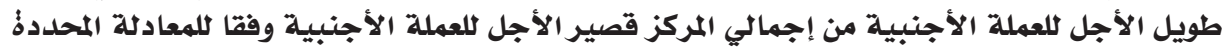

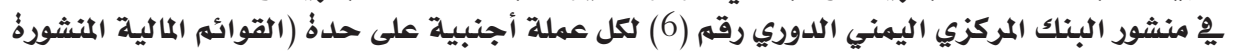

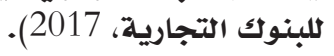

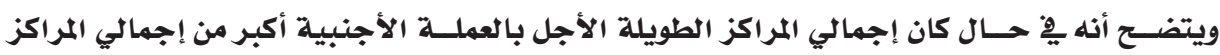

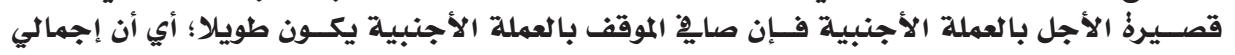

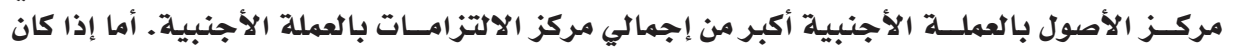

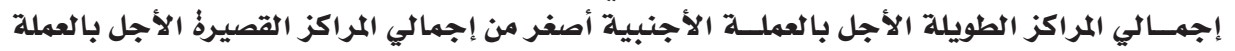

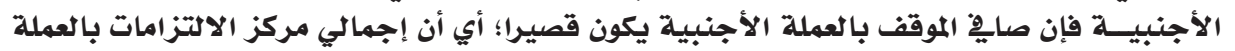

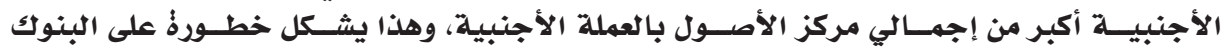
.(Humala, 2019; Altunok, Aytug, \& Oduncu, 2014) 


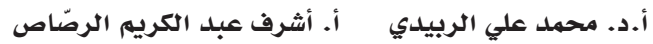

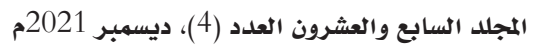

2.قيــاس آثار التغيرات ِِّ أسـعار صرف العملات الأجنبية لصايِّ مراكـز العملات الأجنبية وفقا لمعيار

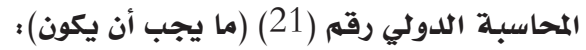

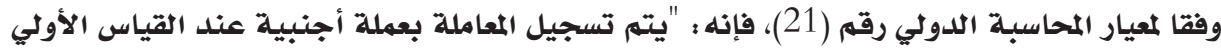

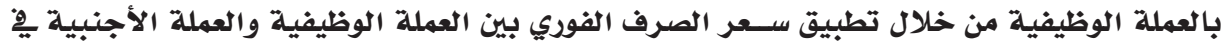

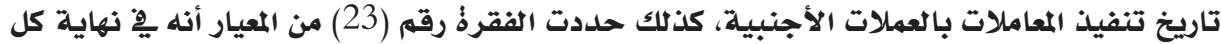

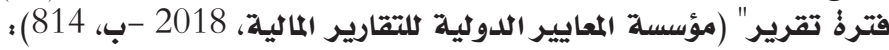
1. يجب ترجمة البنود النقدية الأجنبية باستخدام سعر الإقفال.

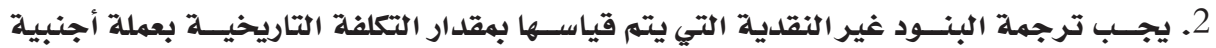

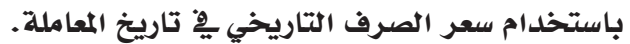

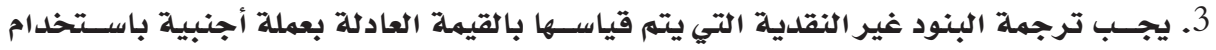

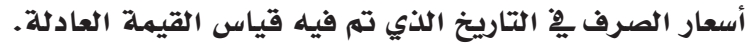

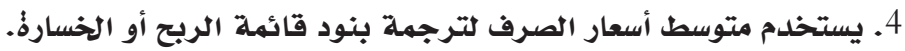

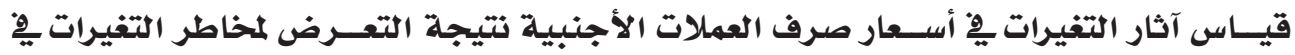
أسعار صرف العملات الأجنبية :

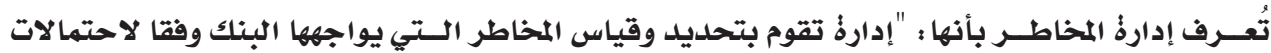

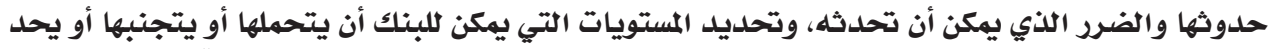

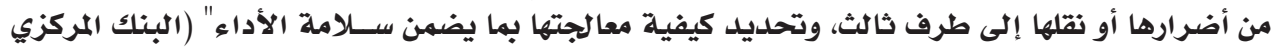

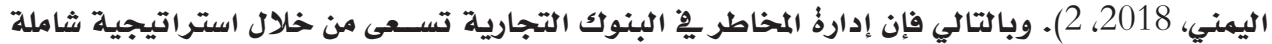

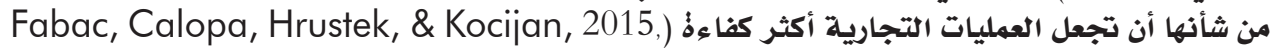

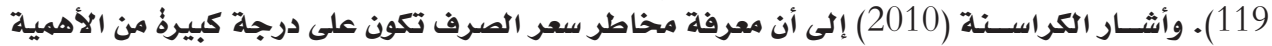

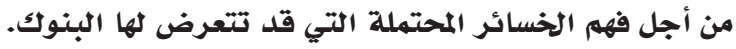

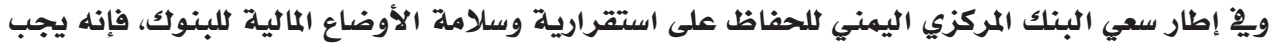

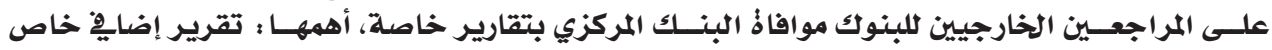

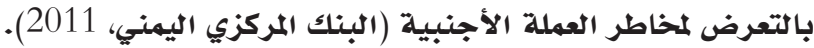

ويمكن قياس آثار التعرض لمخاطر التغيرات ِيْ أسعار صرف العملات وفقا للآتي:

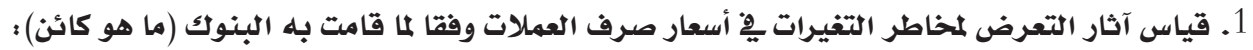

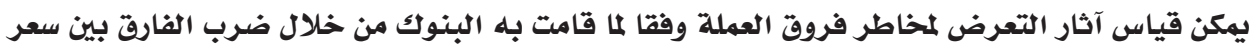

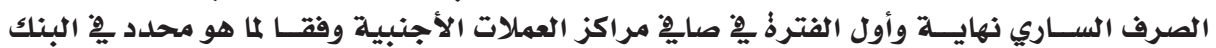

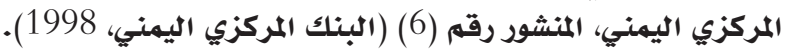

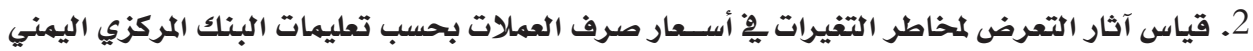
(ما هو كائن):

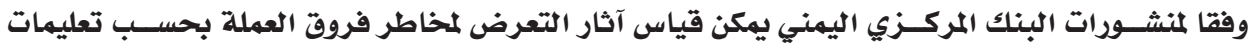

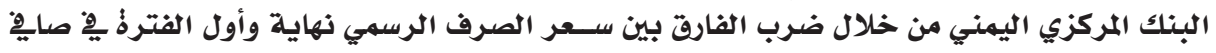

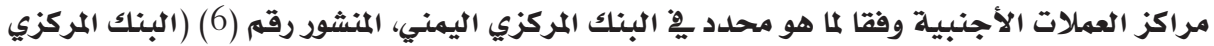

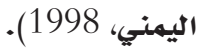
3. قياس آثار التعرض لمخاطر التفيرات فِ أسـعار صرف العملات وفقا لمعيار المحاسبة الدولي رقم (21) (ما يجب أن يكون) 


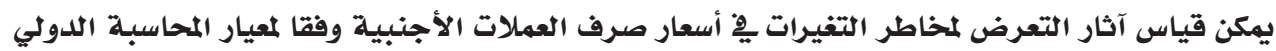

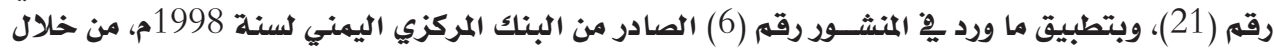

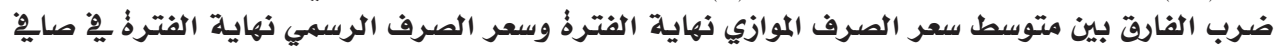
مراكز العملات الأجنبية (البنك المركزي المئوسي اليمني، 1998).

قياس آثار التغيرات يِّ أسـعار صرف العملات الأجنبية لنسبـ مراكز العملات الأجنبية المهمة والقائمة إلى رأس المال والاحتياطيات ألفيرات

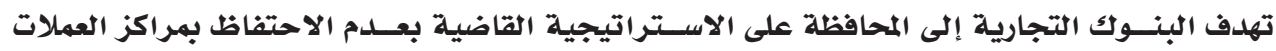

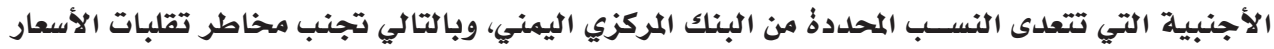
(القوائم المالية المنشورةٌ للبنوك التبدي التجارية، 2017).

ويمكـن قياس آثار التغيرات فِ أســعار صرف العملات الأجنبية لنسـب مراكز العمسلات الأجنبية المهمة

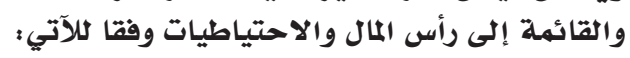

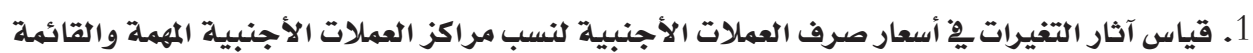

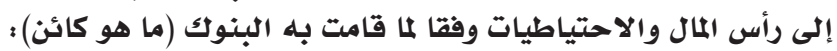

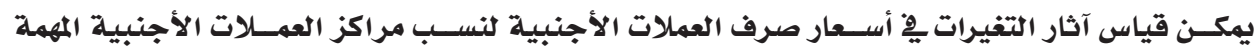

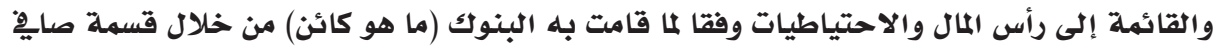

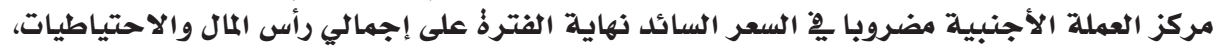

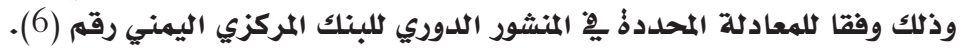

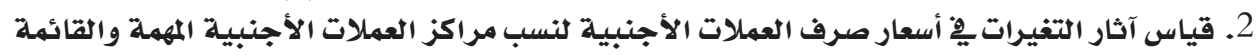

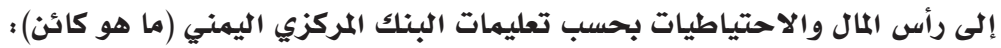

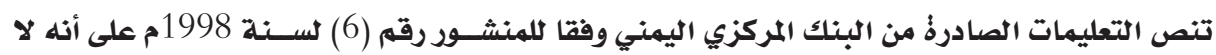

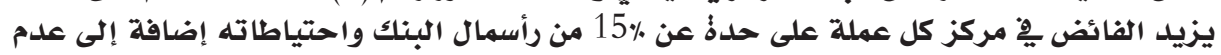

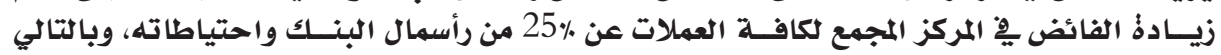

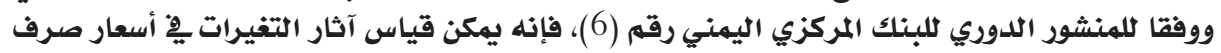

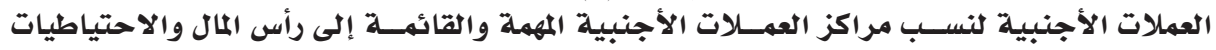

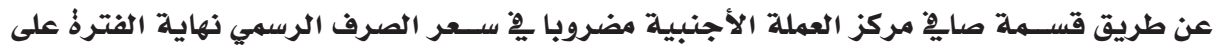

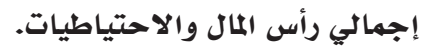

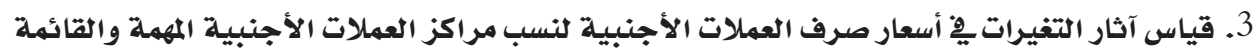

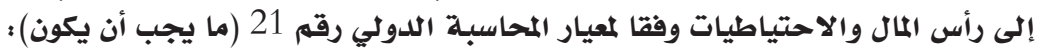

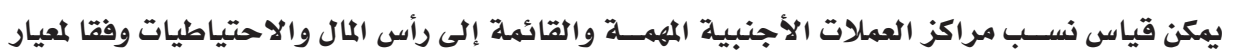

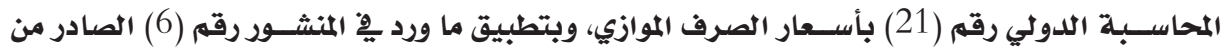

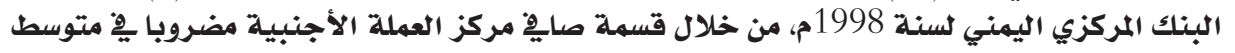

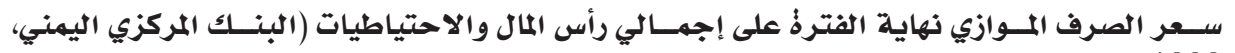
(1998

4. قيـاس آثار التفـيرات فِ القيمة العادلة للمعامـلات بالعملة الأجنبية (تحليل الحساسـية للعملات

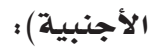

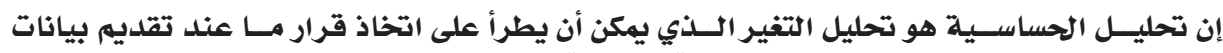

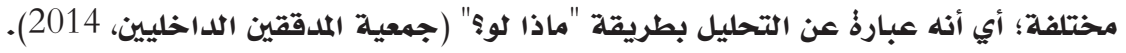




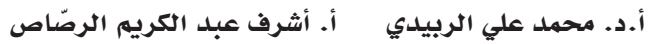

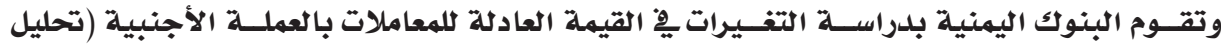

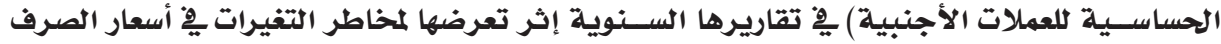

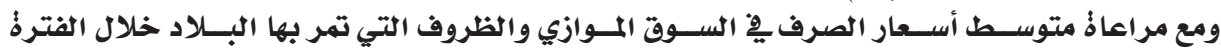

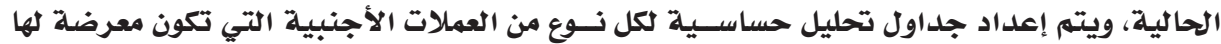

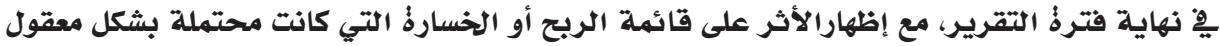

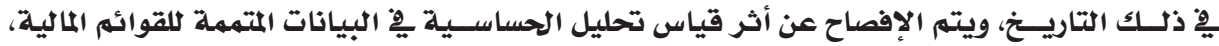

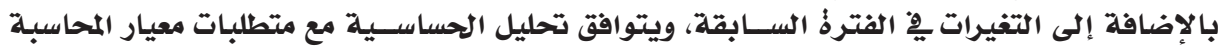

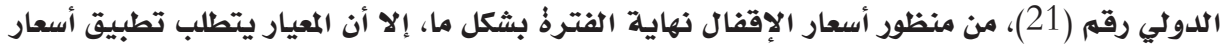

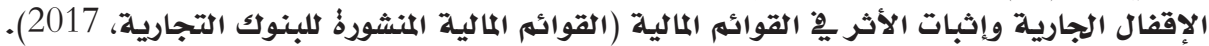

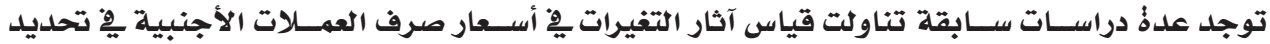

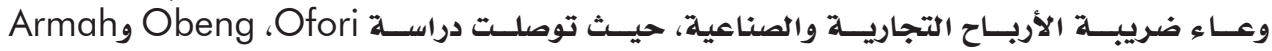

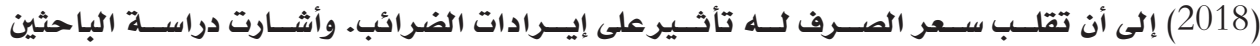
الدخل Harter ،Kawaller McDonald

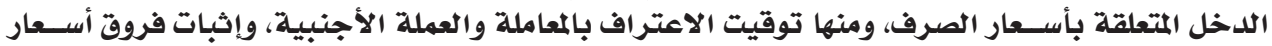

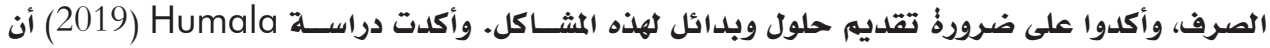

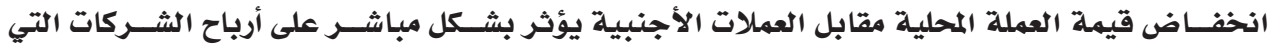

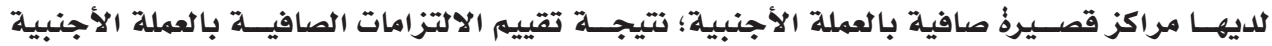

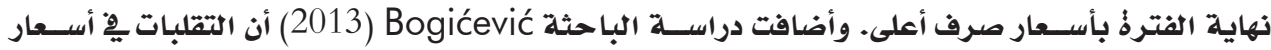

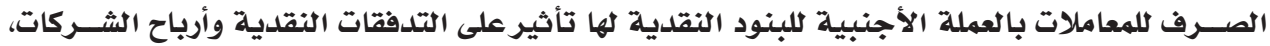

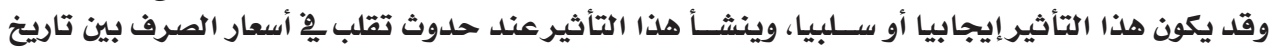

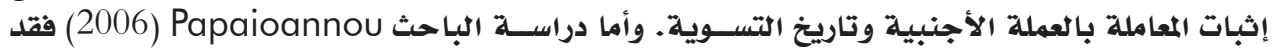

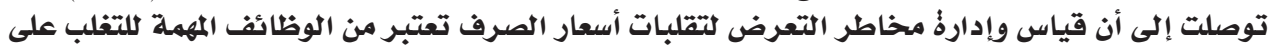

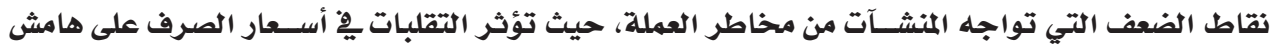

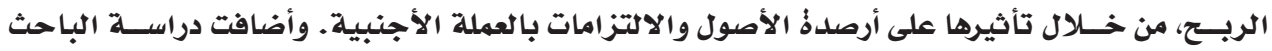
Reem

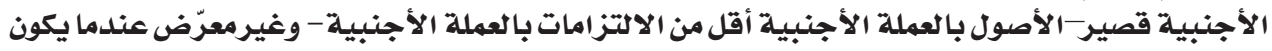

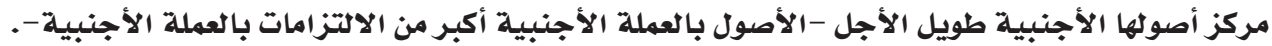

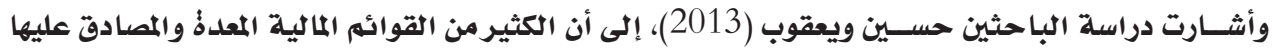

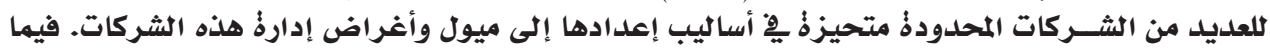

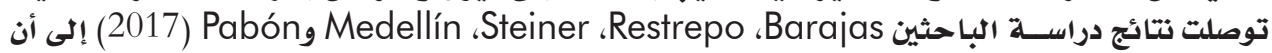

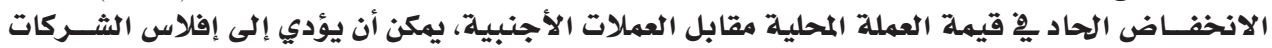

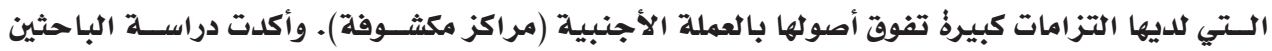
عاتهي Altunok et al.

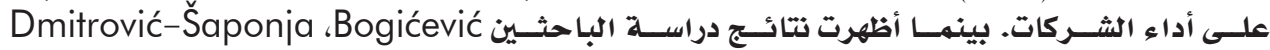
و Pantelić

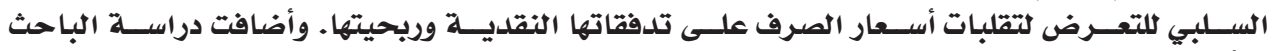
وتحتا Tereščenko

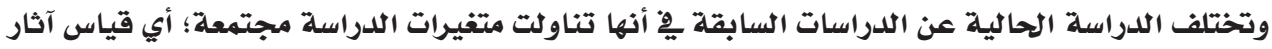

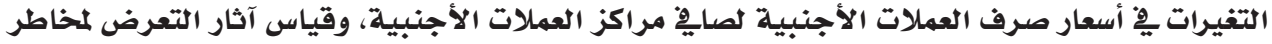

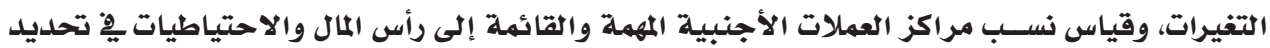

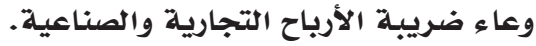




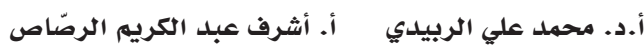

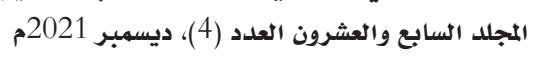

مشكلة الدراسة:

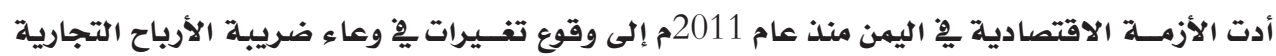

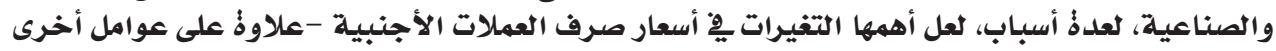
غير مشمولة ِيف الدراسية.

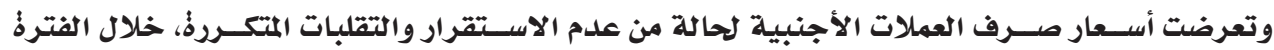

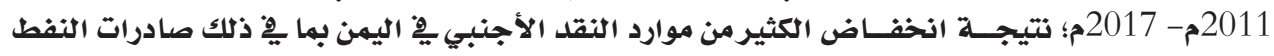

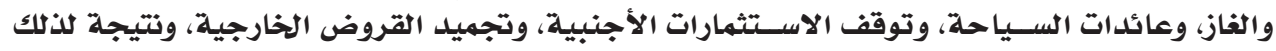

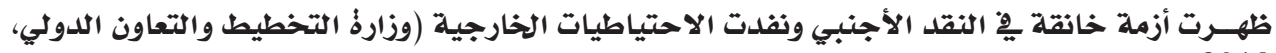

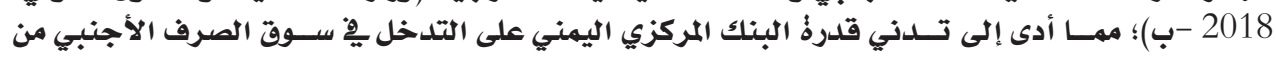

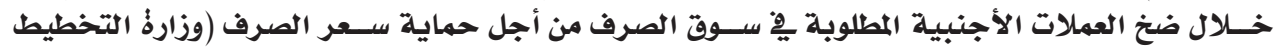
والتعاون الدولي، 2016).

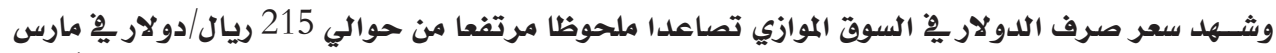

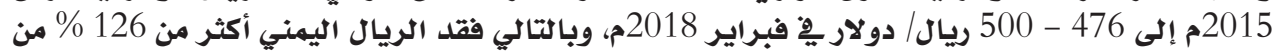

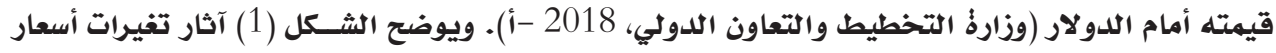

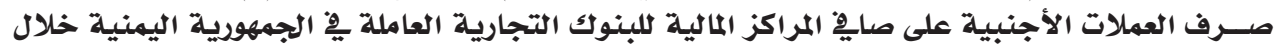

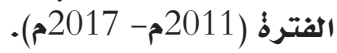

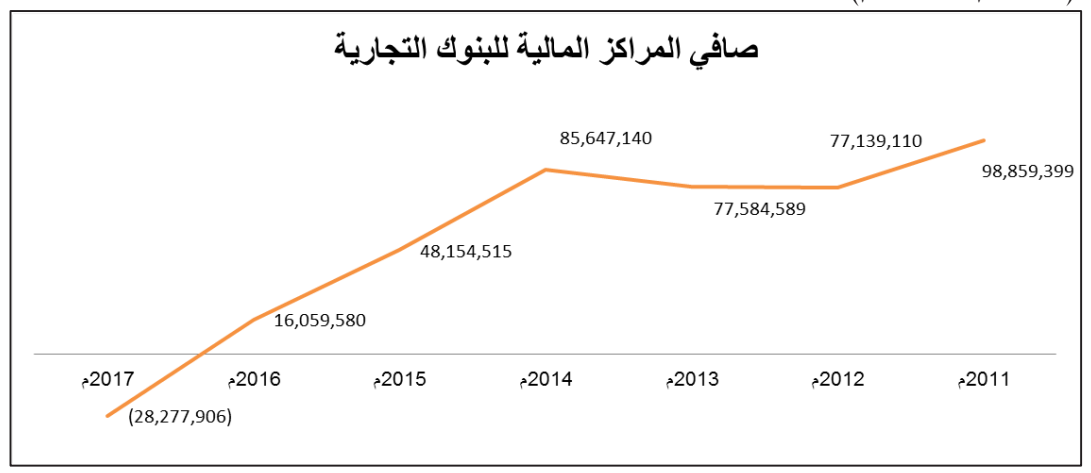

شكل (1): صايْ المراكز المالية للبنوك التجارية خلال الفترة: (2011م- 2017م)

المصدر: التقارير المالية السنوية المنشورةٌ للبنوك التجارية.

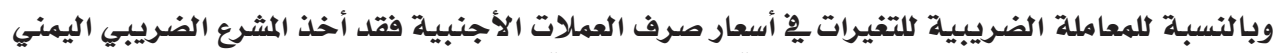

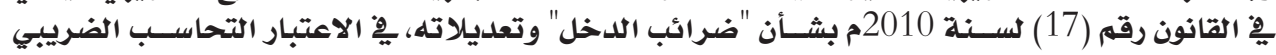
فروقات العملة، دون توضيح طرق قياس فروق العملة عند التهان التحاسب الضريبي.

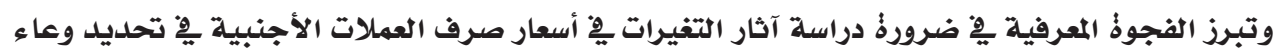

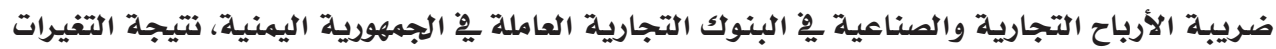

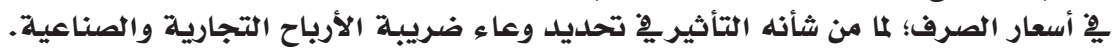

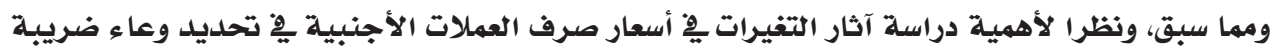

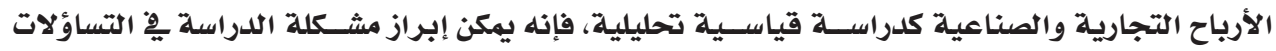

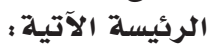

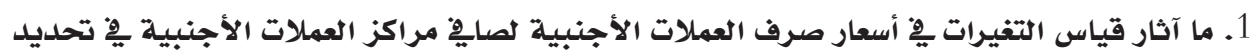

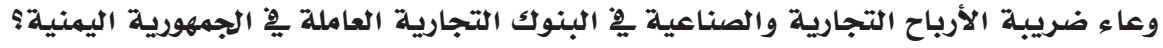


أ.د. محمد علي الربيدي أ. أشرف عبد الكريم الرصّاص الجراص

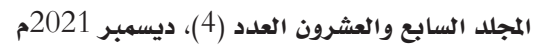

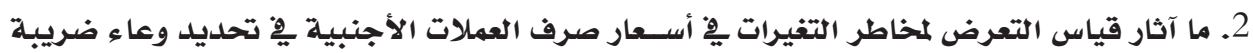

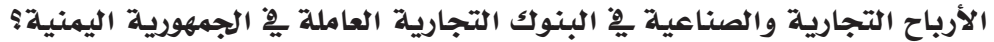

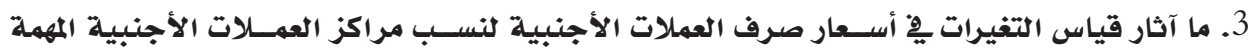

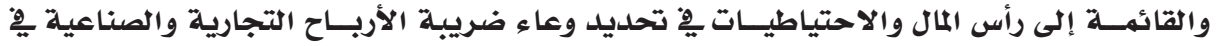

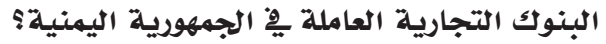

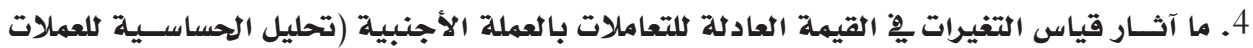

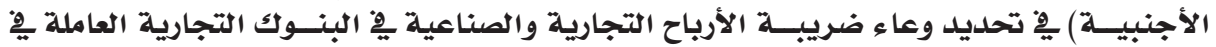

$$
\text { أهداف الدراسهورية اليمنية: }
$$

تسعى الدراسة إلى تحقيق الأهداف الآتية :

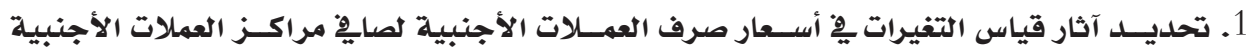

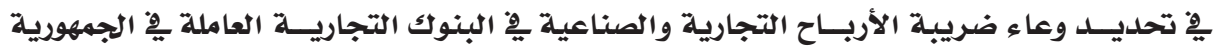
اليمنية.

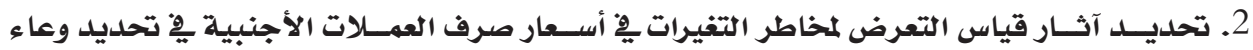

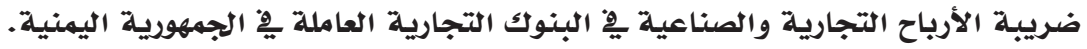

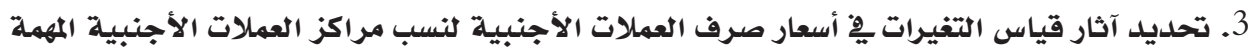

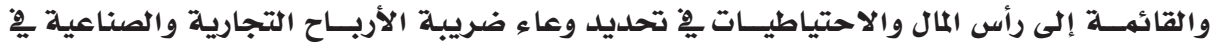

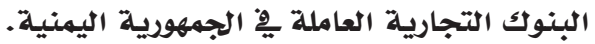

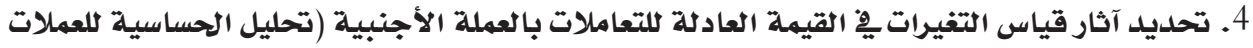

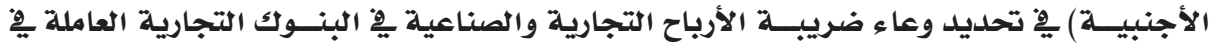

الجمهورية اليمنية الاجنية

أهمية الدراسة:

تكتسب الدراسة أهميتها من الناحية النظريـة والعملية على النحو الآتي:

الأهمية النظرية :

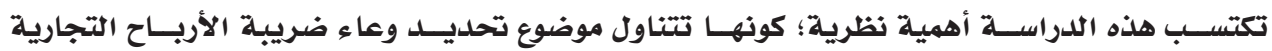

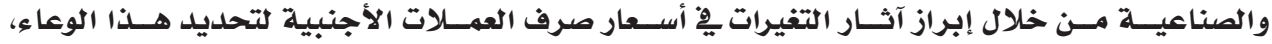

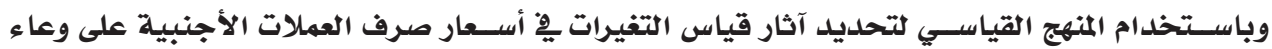

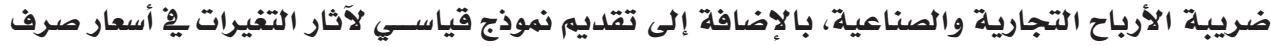

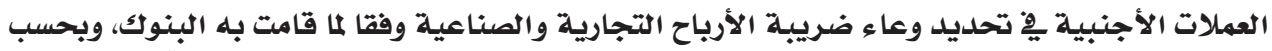

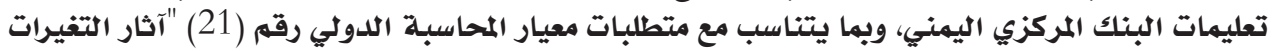

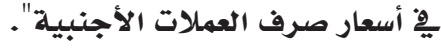

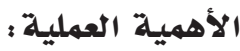

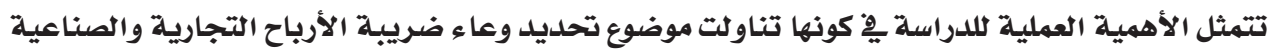

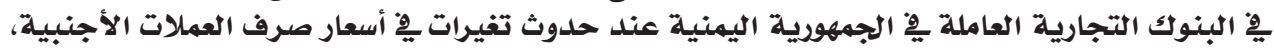

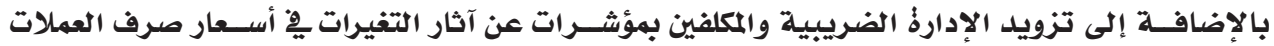

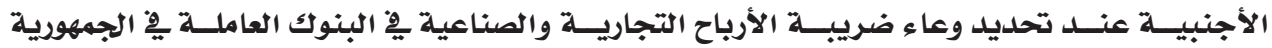

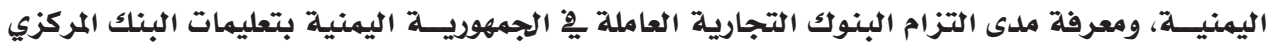

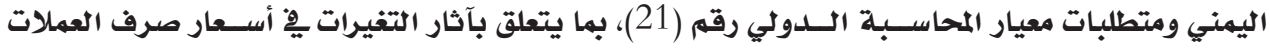




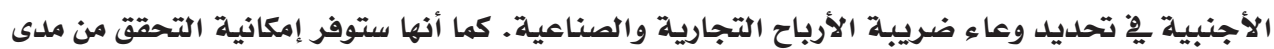

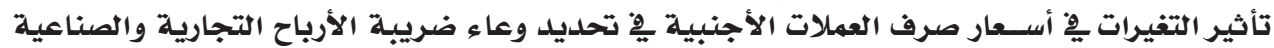

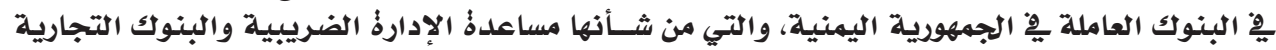

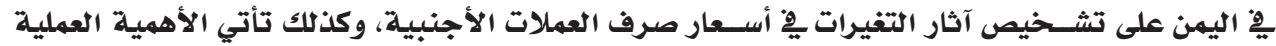

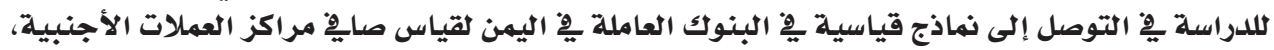

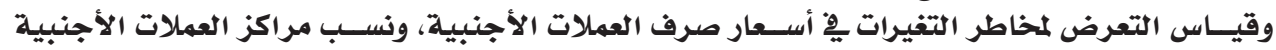

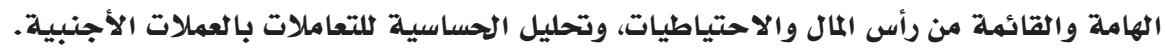

$$
\text { النموذج المعرفي: }
$$

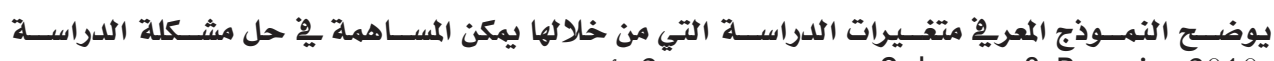

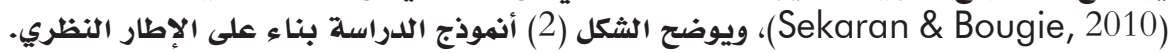

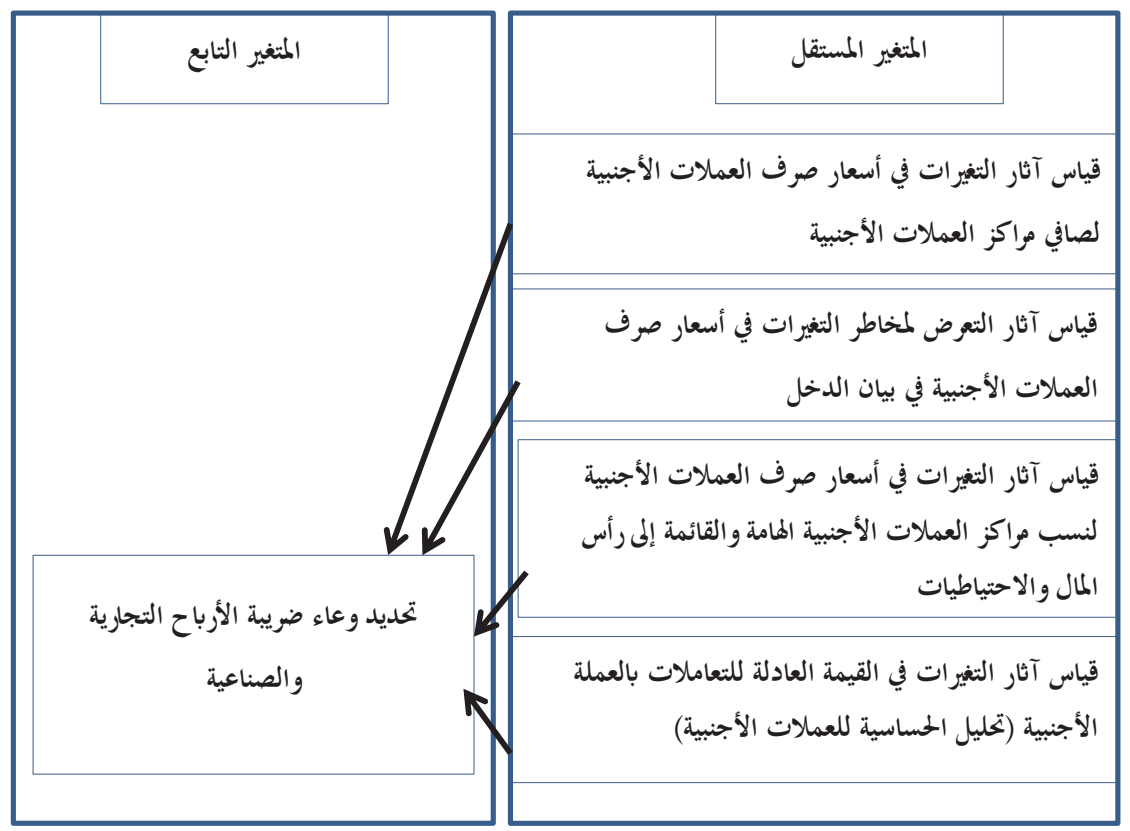

شكل (2) : النهوذج المعربِ

\section{فرضيات الدراسة:}

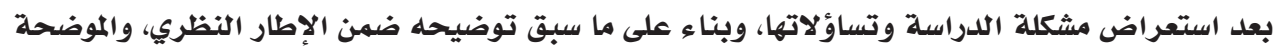

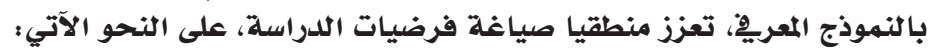

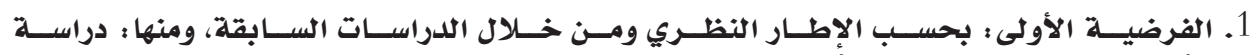
زادت Humala

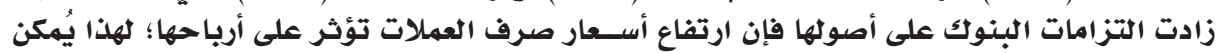

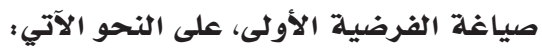

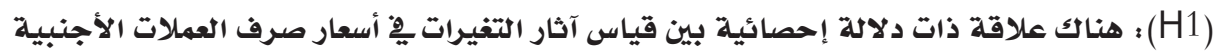

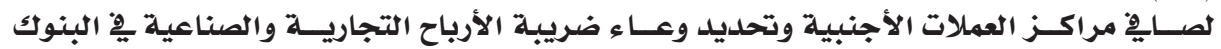
التجارية العاملة يِّاِ الجمهورية اليمنية. 
أ.د. محمد علي الربيدي أ. أشرف عبد الكريم الرصّاص الجراص

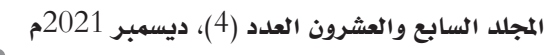

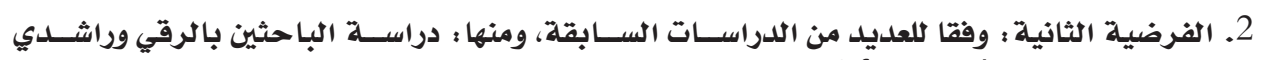

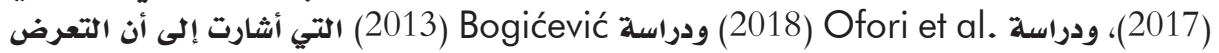

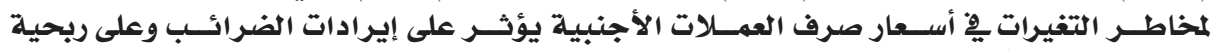

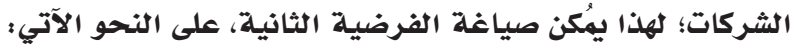

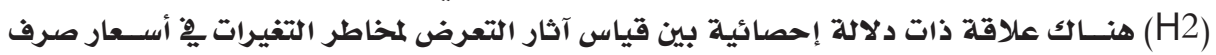

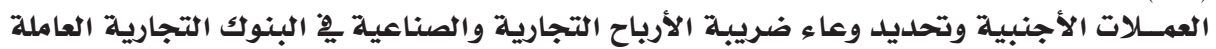
مف الجههوريية اليهنية.

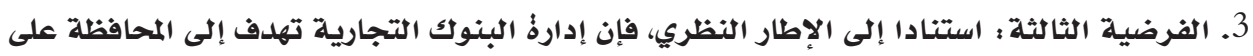

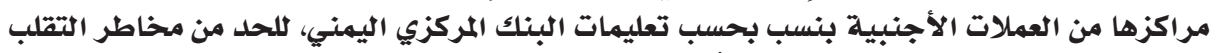

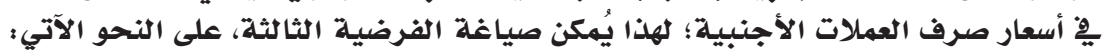

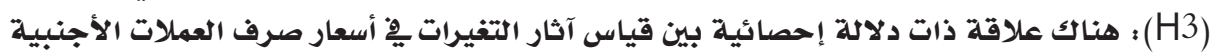

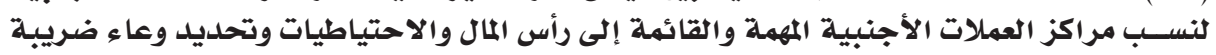

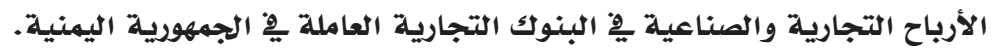

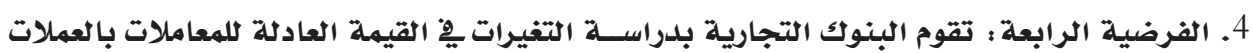

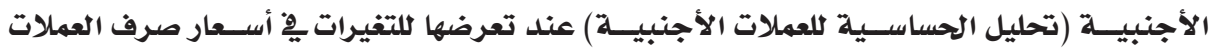

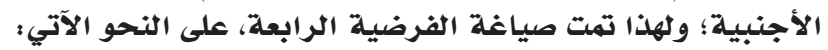

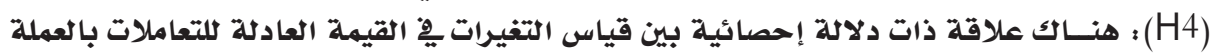

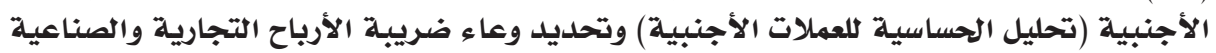

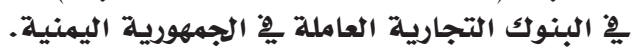
منهجية الدراسة وإجـراءاتها:

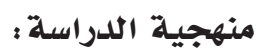

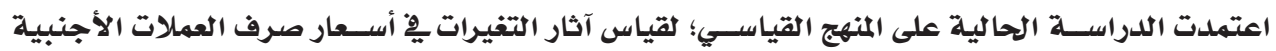

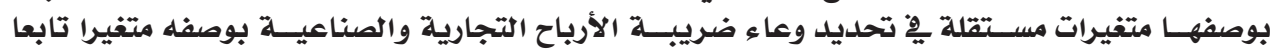

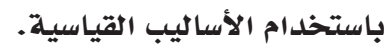
طبيعة البيانات : ماتحات

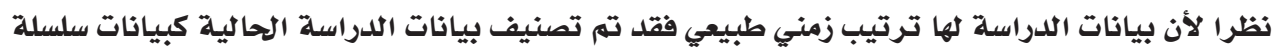

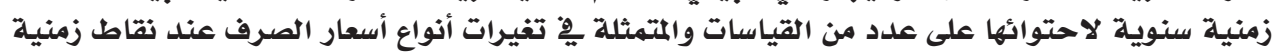

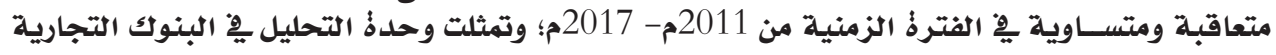

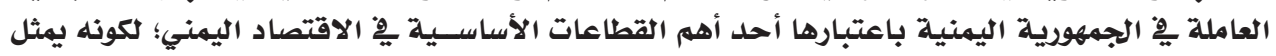

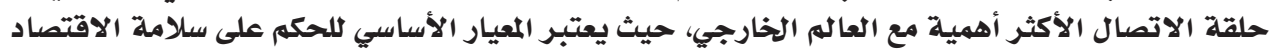

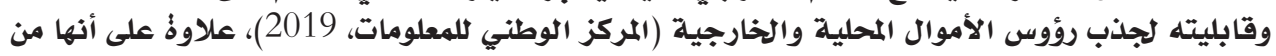

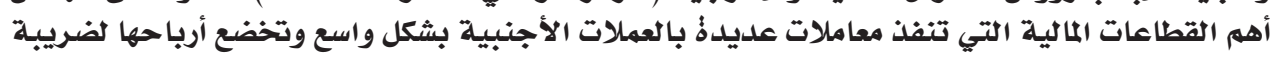
الأرباح التجارية والصناعية.

مجتهع الدراسلة وعينتها :

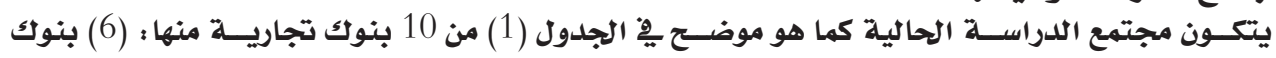

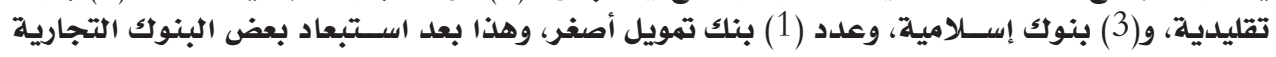
الآتيلة :

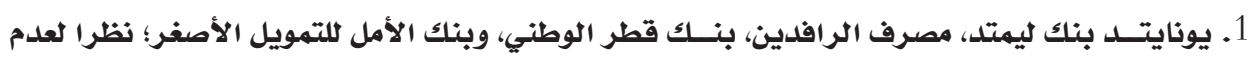

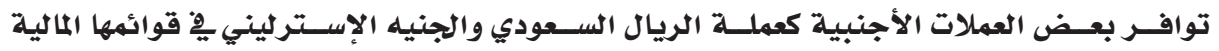
المنشورة. 


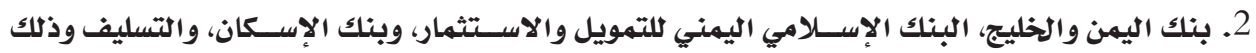

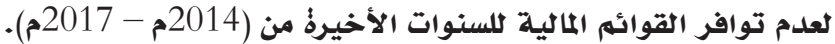

جلدول (1): البنوك التجاريية العاملة بالجمهوريـة اليمنية محل الدراسة

\begin{tabular}{|c|c|c|c|c|c|c|}
\hline \multicolumn{2}{|c|}{ ملكية رأس المال } & \multirow{2}{*}{ (بملايين المال المدفوع } & \multirow{2}{*}{ المركزيسيس } & \multirow{2}{*}{ التأسيس } & \multirow{2}{*}{ التصنيف } & \multirow{2}{*}{ 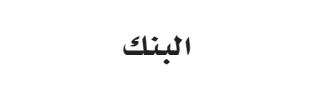 } \\
\hline النسبة\% & الجهةة & & & & & \\
\hline$\% 51$ & الحكومة & 15,000 & صنعاء & 1962 & تقليدي & البنك اليمني للإنشاء والتعمير \\
\hline$\% 49$ & 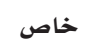 & & & & & \\
\hline$\% 100$ & الحكومة & 10,000 & 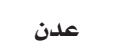 & 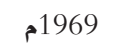 & تقليدي & البنك الأهلي اليمني \\
\hline$\% 100$ & أجنبي & 6,000 & 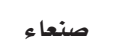 & 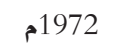 & تقليدي & البنك العربي \\
\hline$\% 85$ & 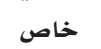 & 15,000 & 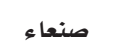 & 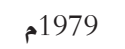 & تقليدي & بنك اليمن الدولي \\
\hline$\% 15$ & أجنبي & & & & & \\
\hline$\% 100$ & 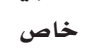 & 6,000 & 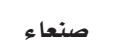 & 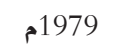 & تقليدي & بنك اليهن الكويت \\
\hline$\% 90$ & 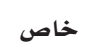 & 8,000 & 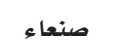 & 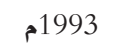 & تقليدي & البنك التجاري اليمني \\
\hline$\% 10$ & الحكومة & & & & & \\
\hline$\% 96.7$ & 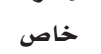 & 20,000 & 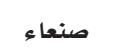 & 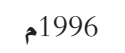 & إسلامي & بنك التضامن الإسلامي الدولي \\
\hline$\% 3.3$ & أجنبي & & & & & \\
\hline$\% 85$ & 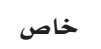 & 9,292 & 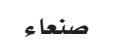 & 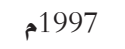 & إسلامي & بنك سباً الإسلامي \\
\hline$\% 15$ & أجنبي & & & & & \\
\hline$\% 57$ & 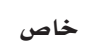 & 6,000 & 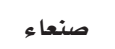 & 2002 & إسلامي & بنك اليمن والبحرين الشامل \\
\hline$\% 43$ & أجنبي & & & & & \\
\hline \multirow[t]{2}{*}{$\% 100$} & 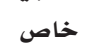 & 10,000 & 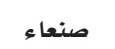 & 2010م & 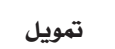 & مصرف الكريمي للتمويل \\
\hline & & & & & أصغر & الأصغر الإسلامي \\
\hline
\end{tabular}

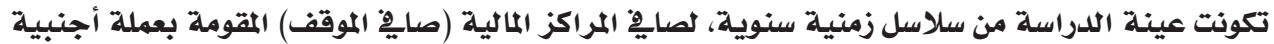

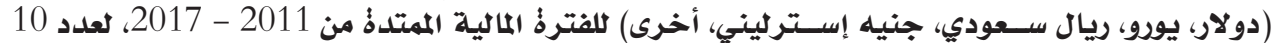

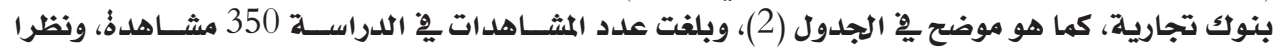

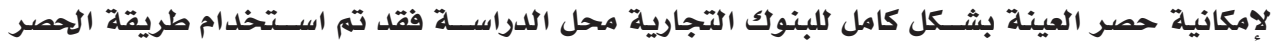

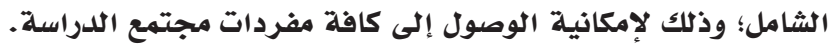
جدول (2) : صايِّ المراكز الماكية للبنوك التجارية العاملة بِّ الجمهورية اليمنية خلال الفترةٌ (2011-2017)

\begin{tabular}{|c|c|c|c|c|c|}
\hline $\begin{array}{c}\text { OTH } \\
\text { الف ريال يهني }\end{array}$ & $\begin{array}{c}\text { SAR } \\
\text { الف ريال يهنسي }\end{array}$ & $\begin{array}{c}\text { GBP } \\
\text { الف ريال يمني }\end{array}$ & $\begin{array}{c}\text { EURO } \\
\text { الف ريال يهني }\end{array}$ & $\begin{array}{c}\text { USD } \\
\text { الف ريال يمني }\end{array}$ & الفترة \\
\hline 51,115 & 24,330 & 3,558 & 3,774 & 16,082 & 2011 \\
\hline 46,285 & 13,254 & 3,959 & (133) & 13,774 & 2012 \\
\hline 48,885 & $(7,098)$ & 5,758 & 2,508 & 27,531 & 2013 \\
\hline 48,497 & 6,309 & 6,192 & 869 & 23,781 & 2014 \\
\hline 22,619 & $(5,467)$ & 311 & $(490)$ & 31,181 & 2015 \\
\hline 33,647 & $(4,703)$ & 1,641 & 448 & $(14,973)$ & 2016 \\
\hline 17,375 & $(17,196)$ & 4,556 & 2,586 & $(35,599)$ & 2017 \\
\hline 268,423 & 9,429 & 25,974 & 9,563 & 61,777 & الإجمالي \\
\hline
\end{tabular}

المصدر : من إعداد الباحث بالاعتماد على القوائم المالية الســنوية المنشــورةٌ للبنوك محل الدراســة للفترة (2011م- 


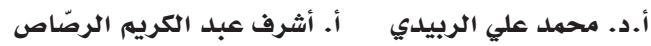

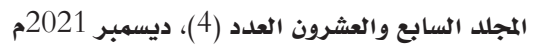

تعيين النهوذج:

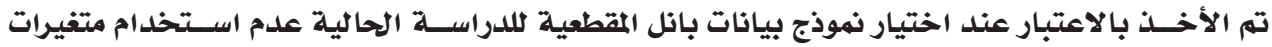

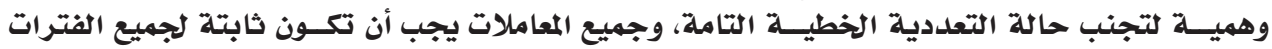

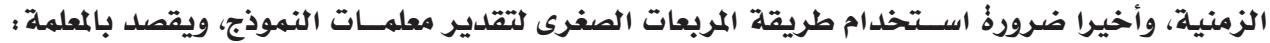

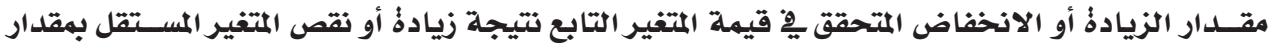

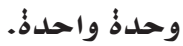

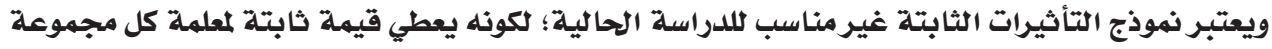

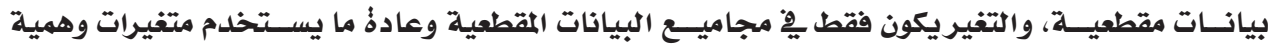

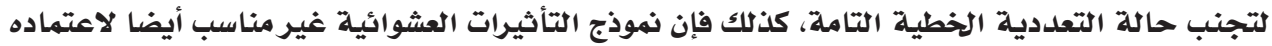

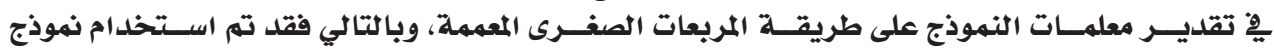

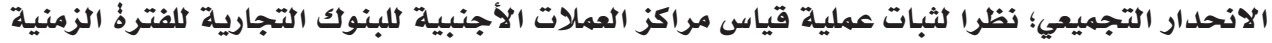

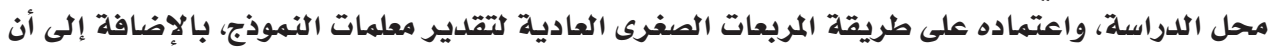

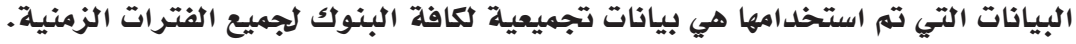
تحلديل وتوصيف متنغيرات النهوذج:

تم تحديل وتوصيف متفيرات الدراسة الحالية كما هو موضح مِِِ الجدول (3). جدول (3) : توصيف متغيرات الدراسة

\begin{tabular}{|c|c|c|}
\hline 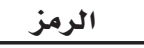 & اسه المتغير & نوع المتغير \\
\hline$Y$ & تحديد وعاء ضريبة الأرباح التجارية والصناعية & 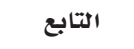 \\
\hline$X_{1}, X_{2}, X_{3}$ & 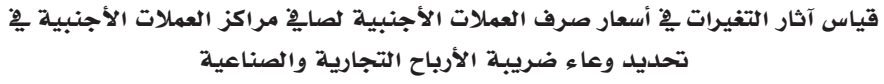 & 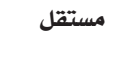 \\
\hline$X_{4}, X_{5}, X_{6}$ & 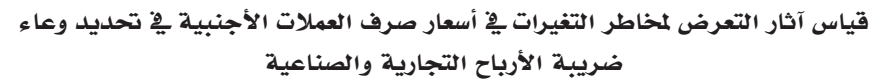 & \\
\hline$X_{7}, X_{8}, X_{9}$ & 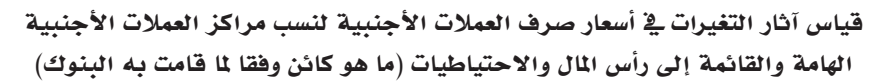 & \\
\hline$x_{10}$ & قياس التغيرات يْ القيمة العادلة للتعاملات بالعملات الأجنبية (تحليل الحساسية & \\
\hline
\end{tabular}

تحلديد الشكل الرياضي للنماذج القياسية للدراسة ؛

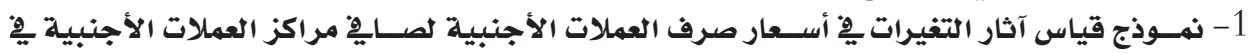

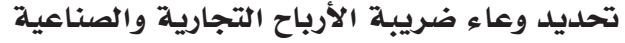

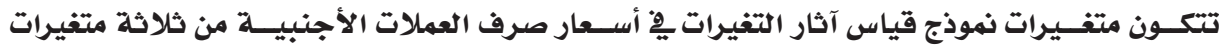

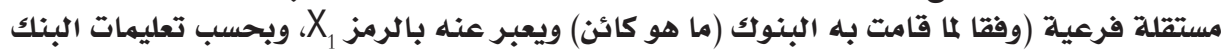

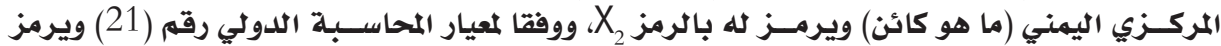

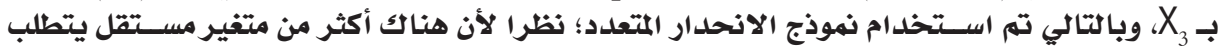

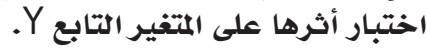

$\mathrm{Y}=\mathrm{C}_{1}+\mathrm{C}_{2} * \mathrm{X}_{1}+\mathrm{C}_{3} * \mathrm{X}_{2}+\mathrm{C}_{4} * \mathrm{X}_{3}$ ا المتغير التابع (تحلديل وعاء ضريبة الأرباح التجارية والصناعية). Y . الحد الثابت (القاطع) 
ا معلمة المتغير المسـتقل لقياس آثار التغيرات ِِّ أسعار صرف العملات الأجنبية لصايِّ مراكز العملات الأجنبية وفقا لما قامت به الماير البنوك.

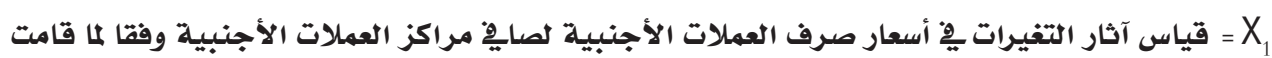
به البنوك.

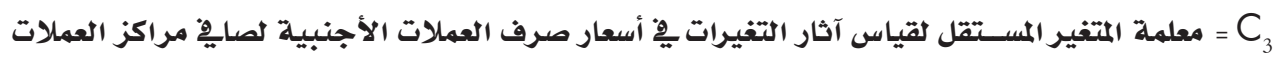

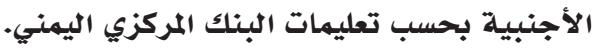

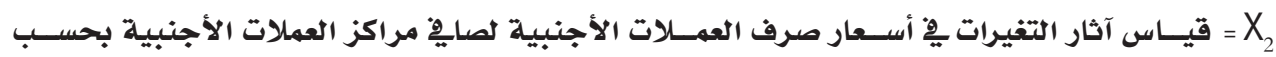
تعليمات البنك المركزي اليمني.

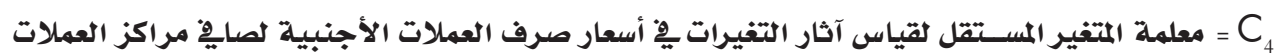
الأجنبية وفقا لمعيار المحاسبة الدولي رقم المبر 21 (IAS No. 21).

X المحاسبة الدولي رقم 21 (IAS No. 21).

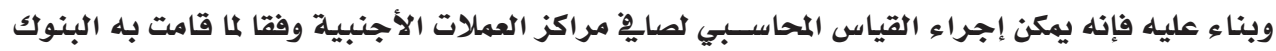

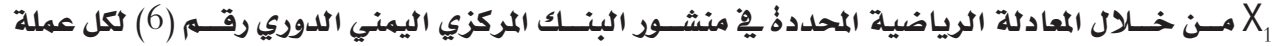

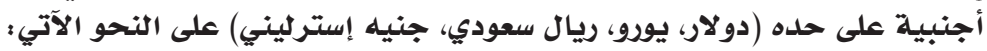

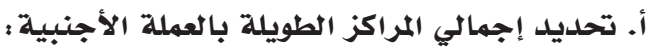

يمكن تحديد إجمالي المراكز الطويلة بالعملة الأجنبية وفقا للمعادلة الآتية ؛ إجهالي المركز الطويل للعهلة الأجنبية = إجهالي الأصول فِ المركز المالي بالعهلة الأجنبية

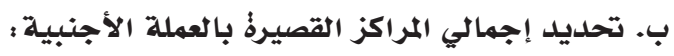
يمكن تحلديل إجمالي المراكز الطويلة بالعملة الأجنبية وفقا للمعادلة الآتية : إجهالي المركز القصيرللعهلة الأجنبية = إجمالي الالتزامات فِ المركز المالمي بالعهلة

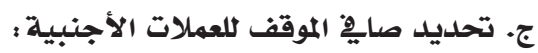

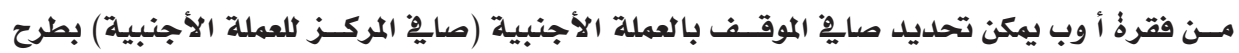

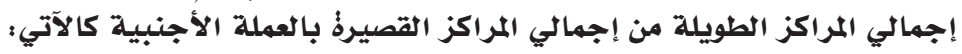

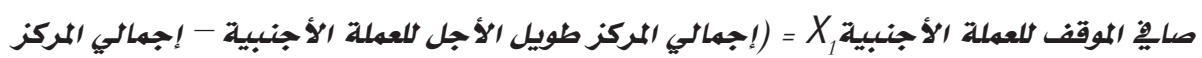

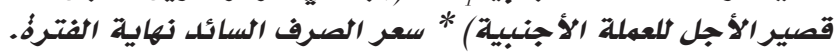

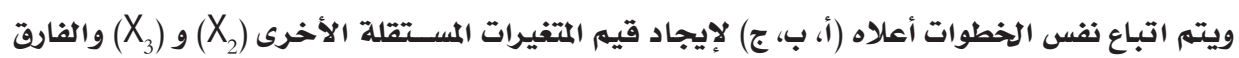

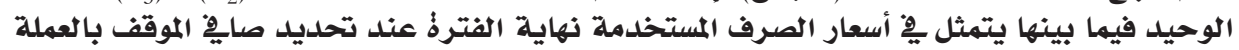
الأجنبية (الفقرة؛ ج)، حيث إنمثل

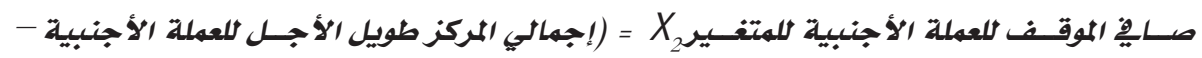

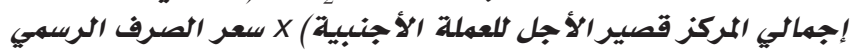

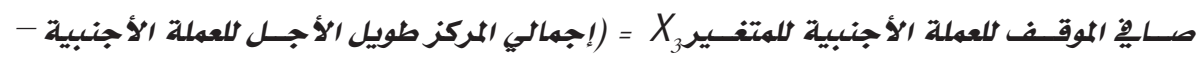

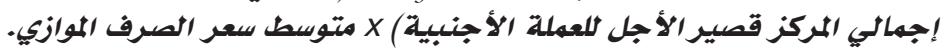


أ.د. محمد علي الربيدي أ. أشرف عبد الكريم الرصّاص الجراص

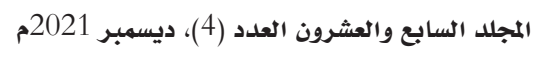

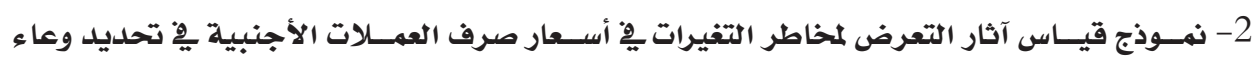

$\mathrm{Y}=\mathrm{C}_{1}+\mathrm{C}_{2} * \mathrm{X}_{4}+\mathrm{C}_{3} * \mathrm{X}_{5}+\mathrm{C}_{4} * \mathrm{X}_{6}$

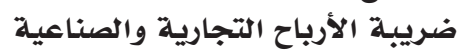

حيث إن :

معلمات المتغيرات المسـقتلة لقياس آثار التعرض لمخاطر التغيرات ِيْ أسـعار صرف العملات $=C_{2}, C_{3}, C_{4}$ الأجنبية X

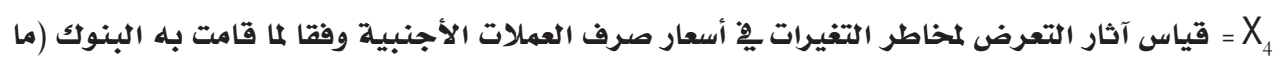
هو كائن).

X المركزي اليهني (ما هو كائن).

X6 المحاسبة الدولي رقم 21 (IAS No. 21) (ما يجب آنار التعرض أن يكون).

ويمكن توضيح آلية قياس متغيرات آثار التعرض لمخاطر التغيرات يِّ أسعار صرف العملات الأجنبية، وذلك على النحو الآتي:

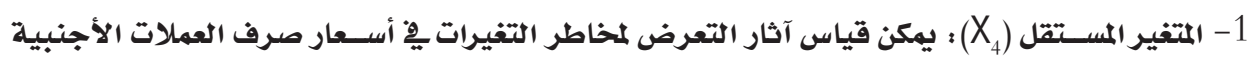

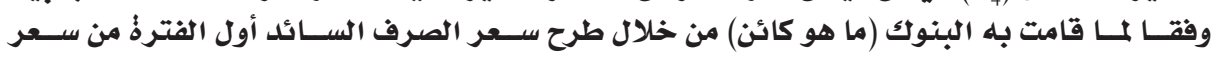

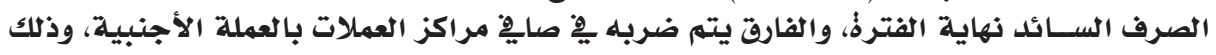

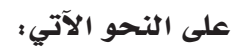

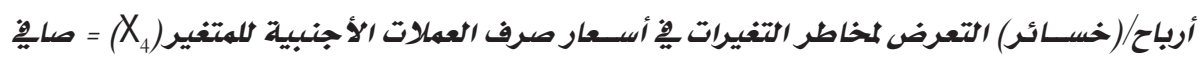

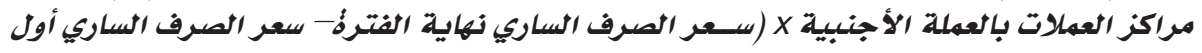
الفترة:).

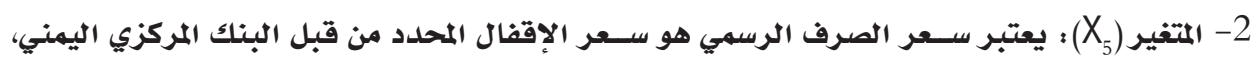

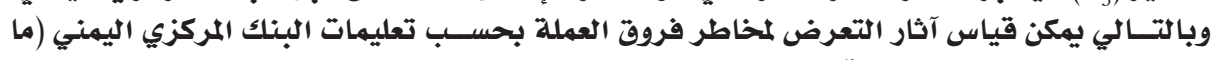

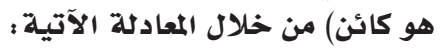

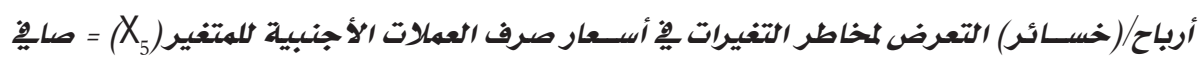

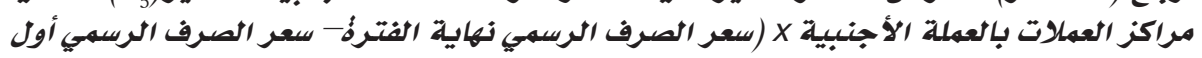
الفترة:)

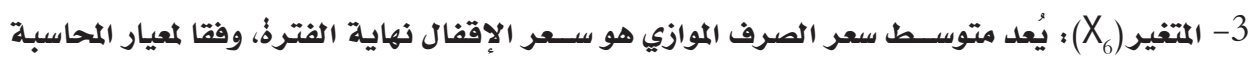

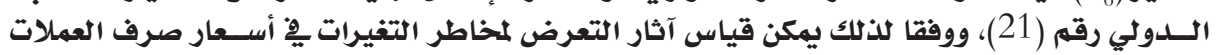

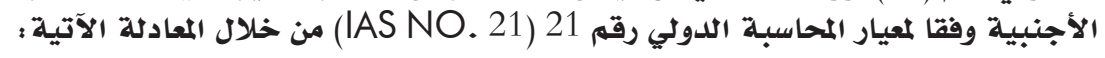

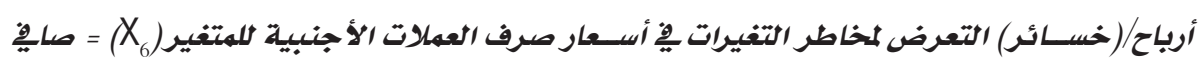

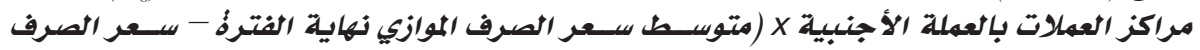
الرسبهي نهاية الفترثة).

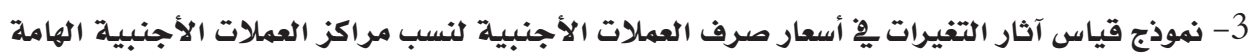

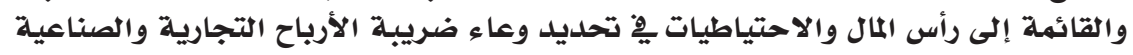

$\mathrm{Y}=\mathrm{C}_{1}+\mathrm{C}_{2} * \mathrm{X}_{7}+\mathrm{C}_{3} * \mathrm{X}_{8}+\mathrm{C}_{4} * \mathrm{X}_{9}$ 
يتكون النهوذج الثالث من ثلاث متغيرات مستقلة رئيسة حيث إن ؛

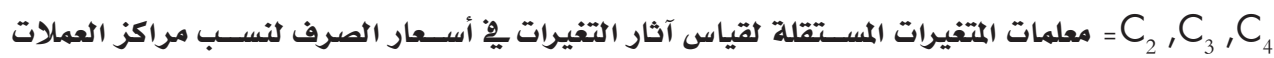

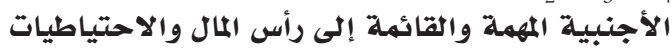

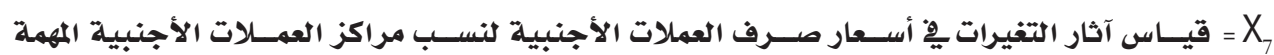
والقائمة إلى رأس المال والاحتياطيات وفقا وات ألما قامت به البه البنوك (ما هو كائن).

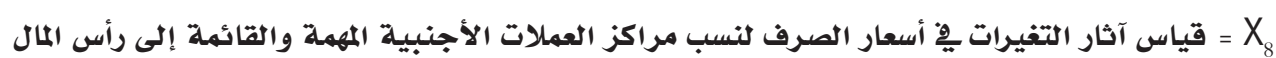
والاحتياطيات بحسب تعليمات البنك المركزي X = X $_{9}$

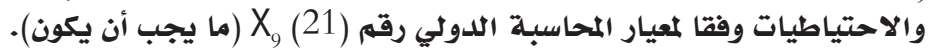

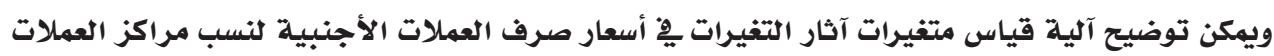

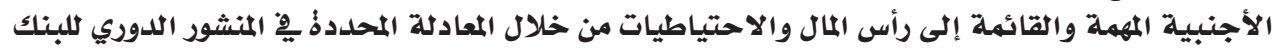

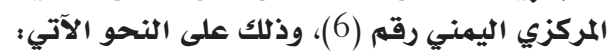
: X

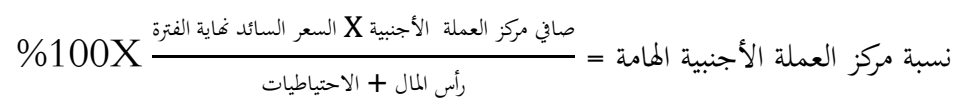
: X

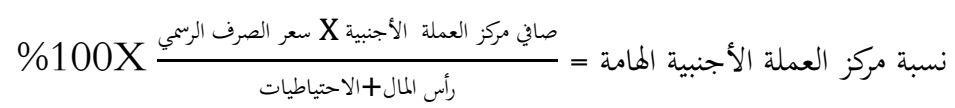
: X

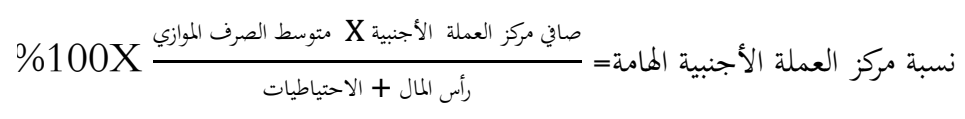

4- نموذج قياس آثار التغيرات ِِّ القيمة العادلة للتعاملات بالعملة الأجنبية (تحليل الحساسية للعملات

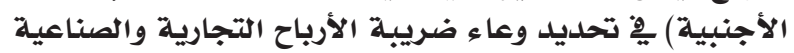
$\mathrm{Y}=\mathrm{C}_{1}+\mathrm{C}_{2} * \mathrm{X}_{10}$

يتكون النموذج الرابع من المتغير X تحليل الحساسية = الأثر المتوقع على قائهة اللدخل لكل عهلة على حلدة Y

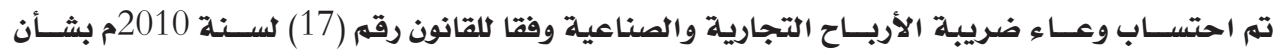

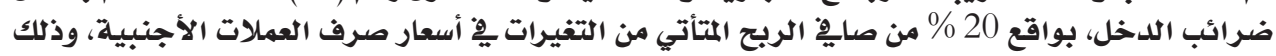

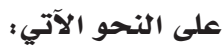

$$
\text { أرباح/(خسائر) أسعار صرف العهلات الأجنبية * } 20 \text { \% }
$$




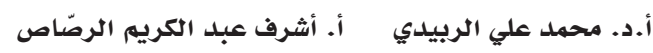

المجلد السابع والعشرون العدد (4)، ديسمبر 2021م أريدي الكريب الرصاصن

\section{الأساليب الإحصائية المستخدمة:}

تمّ الاعتماد على الأساليب الإحصائية الآتية لاختبار فرضيات الدراسة ؛

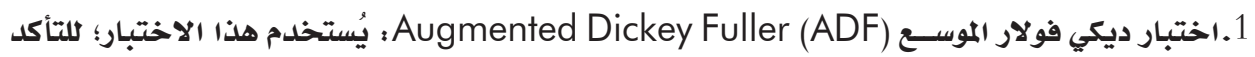

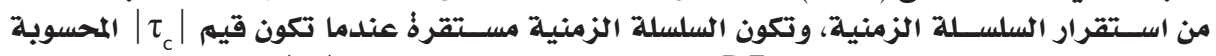

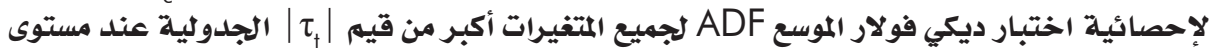
معنوية (0.05) (عطيه، 2005).

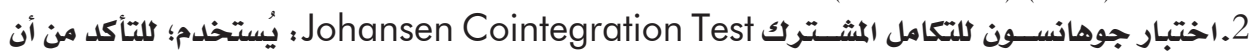

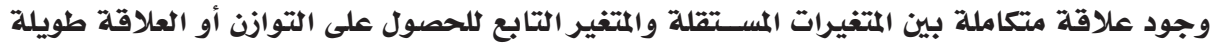

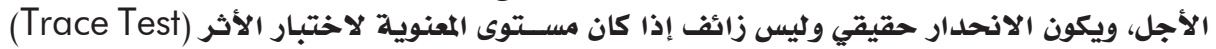

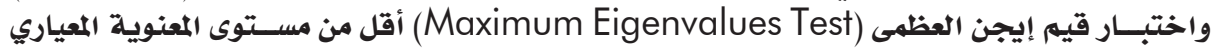

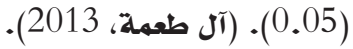

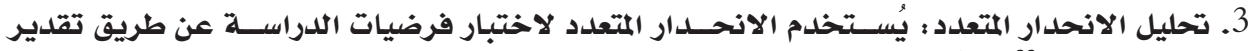

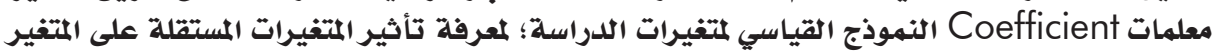
التابع (جيجاراتي، 2015).

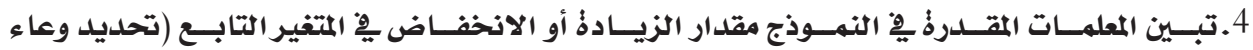

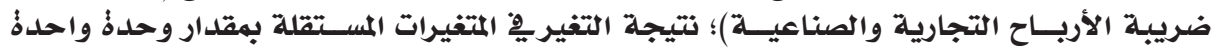

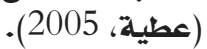

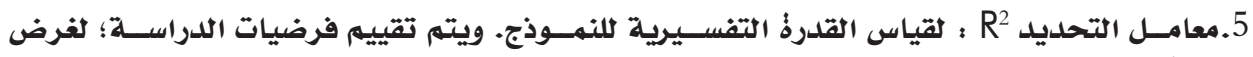

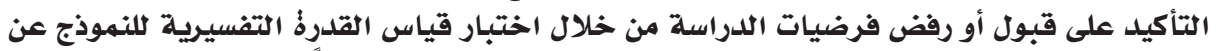

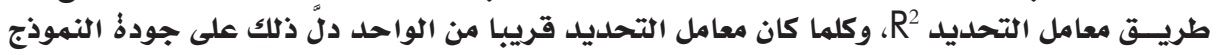

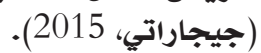

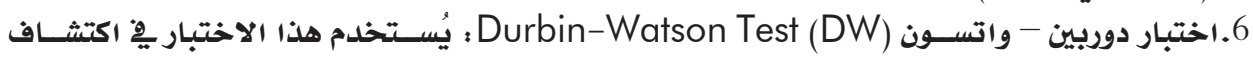

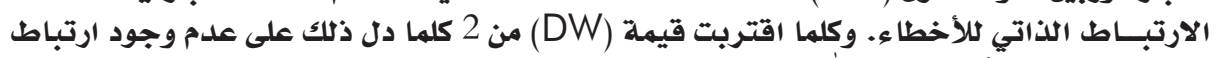

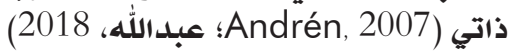

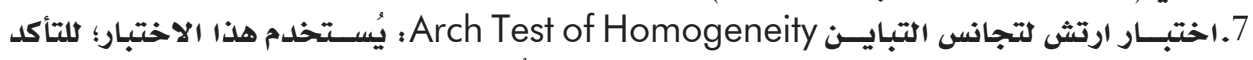

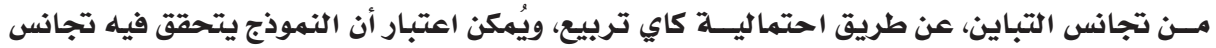

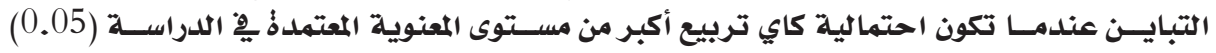

$$
\text { (جيجاراتي، 2015). }
$$

اختبار استقرار السلاسل الزمنية لمتغيرات الدارسة القياسية - اختبار ديكي- فولر :

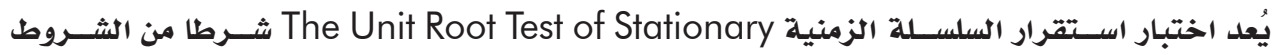

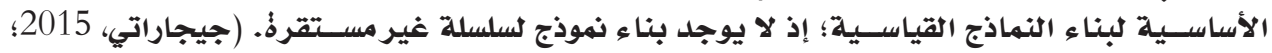

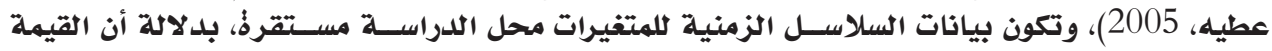

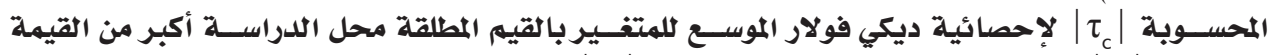

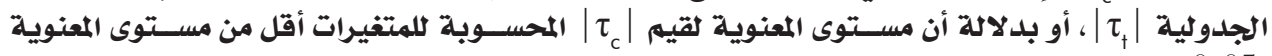

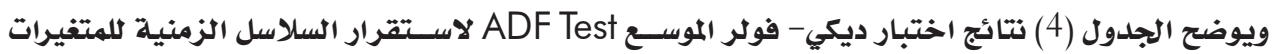
المستقلة X, 


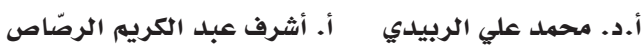

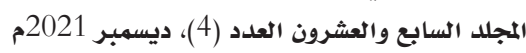

جلدول (4): نتائج اختبار ديكي- فولر الموسع لاستقرار السلاسل الزمنية لعناصر متفيرات الدارسة

\begin{tabular}{|c|c|c|c|c|}
\hline \multirow{4}{*}{$\begin{array}{l}3 \\
\frac{3}{3} \\
3 \\
3\end{array}$} & \multicolumn{3}{|c|}{ المستوى،LEVEL } & \multirow{3}{*}{ ADF TEST } \\
\hline & \begin{tabular}{|c|} 
None \\
بدون وجود قاطع وبدون اتجاه
\end{tabular} & $\begin{array}{c}\text { Intercept/ Constant } \\
\text { بوجو: قاطع وبدون اتجاه } \\
\text { C } \\
\end{array}$ & $\begin{array}{c}\text { Trend \& Intercept } \\
\text { بوجود قاطع واتجاه } \\
\text { @TREND("1") }\end{array}$ & \\
\hline & النموذج 1 & النموذج 2 & النموذج & \\
\hline & -1.942 & -2.869 & -3.422 & القيم الرجة عند مستوى معنوية 5\% (قيم t الجدولية) \\
\hline $\mathrm{I}(0)$ & -3.440 & -4.469 & -4.095 & قيمة tc المدسوبة للمتغير Y \\
\hline I(0) & -2.678 & -2.909 & -2.770 & لقيمة tc المدسوبة للمتغير X1 \\
\hline $\mathrm{I}(0)$ & -2.653 & -2.945 & -2.768 & قيمة tc المدسوبة للمتغير X3 \\
\hline I(0) & -8.869 & -9.165 & -8.974 & قيمة tc المدسوبة للمتغير X4 \\
\hline $\mathrm{I}(0)$ & -10.845 & -11.218 & -10.884 & قيمة tc المدسوبة للمتغير X5 \\
\hline $\mathrm{I}(0)$ & -3.603 & -4.563 & -4.040 & قيمة tc المدسوبة للمتغير X6 \\
\hline I(0) & -4.119 & -4.687 & -4.355 & قيمة tc المدسوبة للمتغير X7 \\
\hline I(0) & -3.441 & -4.106 & -3.842 & قيمة tc المدسوبة للمتغير X8 \\
\hline $\mathrm{I}(0)$ & -4.632 & -5.289 & -4.732 & قيمة tc المدسوبة للمتغنير X9 \\
\hline I(0) & -5.587 & -6.012 & -5.580 & قيمة tc المدسوبة للمتيز X10 \\
\hline
\end{tabular}

EViews V.10 المصدر: مخرجات برنامج

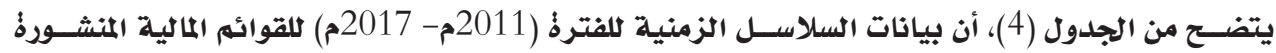

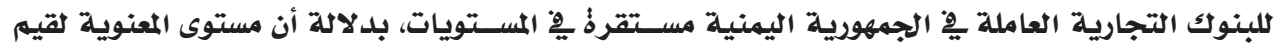

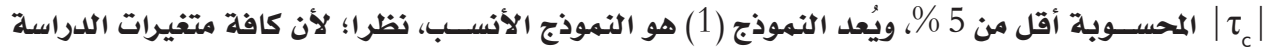

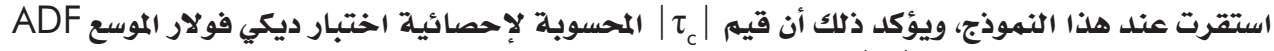

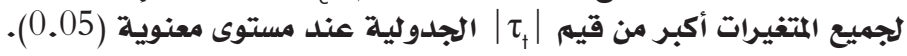

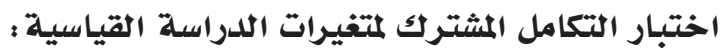

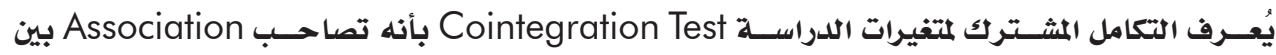

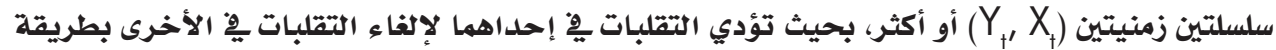

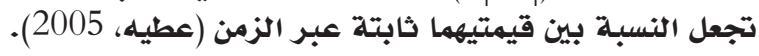

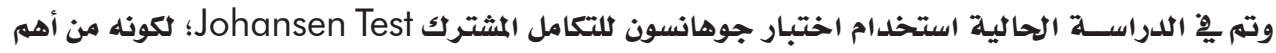

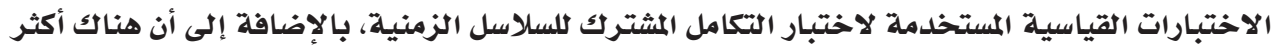

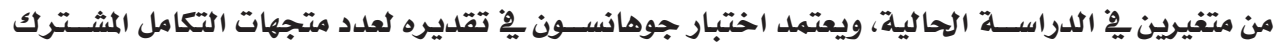

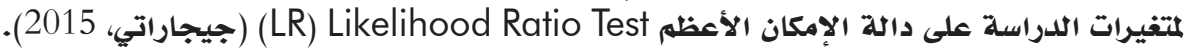

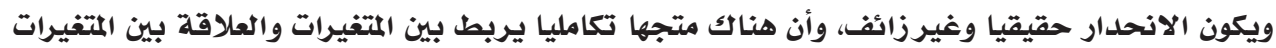

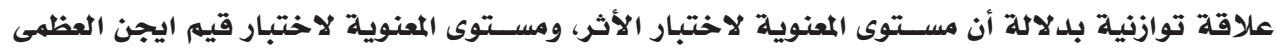

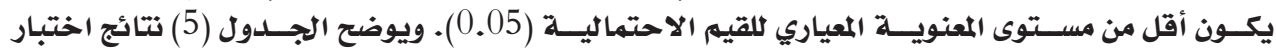

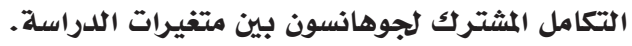


أ.د. محمد علي الربيدي أ. أشرف عبد الكريم الرصّاص الجراص

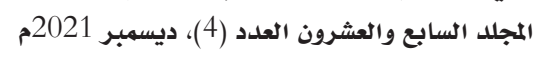

جدول (5) : نتائج اختبار جوهانسون للتكامل المشترك لمتغيرات الدراسة

اختبار الأثر واختبار قيم إيجن العظمى

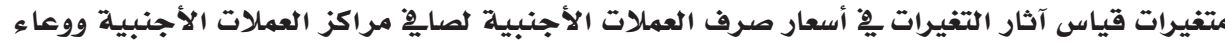
Y، X, X, X

\begin{tabular}{|c|c|c|c|c|c|c|}
\hline متجهات التكامل & القيمة الذاتية & $\begin{array}{c}\text { الأثائية } \\
\lambda_{\text {Trac }} \\
\end{array}$ & الاحتمائية الإلية & قإحيه إيجئية & الاحتمالية & المعنوية \\
\hline $\begin{array}{l}\text { Hypothesized } \\
\text { No. of CE (s) }\end{array}$ & Eigenvalue & $\begin{array}{l}\text { Trace } \\
\text { Statistic }\end{array}$ & $\begin{array}{l}0.05 \\
\text { Critical } \\
\text { Value }\end{array}$ & $\begin{array}{l}\text { Max- } \\
\text { Eigen } \\
\text { Statistic }\end{array}$ & $\begin{array}{l}0.05 \\
\text { Critical } \\
\text { Value }\end{array}$ & Prob.** \\
\hline None $^{*}$ & 0.123584 & 65.82150 & 24.27596 & 45.51050 & 17.79730 & 0.0001 \\
\hline At most $1^{*}$ & 0.038173 & 20.31099 & 12.32090 & 13.42780 & 11.22480 & 0.0000 \\
\hline At most $2^{*}$ & 0.019754 & 6.883193 & 4.129906 & 6.883193 & 4.129906 & 0.0026 \\
\hline
\end{tabular}

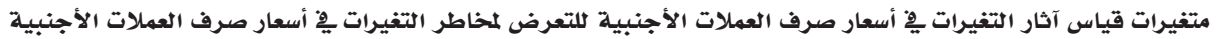

Y، X,

\begin{tabular}{ccccccc}
\hline None $^{*}$ & 0.410739 & 320.4904 & 40.17493 & 182.4655 & 24.15921 & 0.0001 \\
At most 1 & 0.209847 & 138.0249 & 24.27596 & 81.25760 & 17.79730 & 0.0000 \\
At most 2 $^{*}$ & 0.126823 & 56.76730 & 12.32090 & 46.87773 & 11.22480 & 0.0000 \\
At most 3 $^{*}$ & 0.028512 & 9.979573 & 4.129906 & 9.979573 & 4.129906 & 0.0000 \\
\hline
\end{tabular}

قياس آثار التغيرات يوّا أسعار صرف العملات الأجنبية لنسب مراكز العملات الأجنبية الهامة والقائمة إلى رأس المال

Y، X

\begin{tabular}{|c|c|c|c|c|c|c|}
\hline None $^{*}$ & 0.166188 & 145.3726 & 40.17493 & 24.15921 & 24.15921 & .0001 \\
\hline At most $1^{*}$ & 0.139952 & 82.67000 & 24.27596 & 17.79730 & 17.79730 & .0000 \\
\hline At most $2^{*}$ & 0.056891 & 30.65538 & 12.32090 & 11.22480 & 11.22480 & .0000 \\
\hline At most $3^{*}$ & 0.029829 & 10.44773 & 4.129906 & 4.129906 & 4.129906 & .0013 \\
\hline \multicolumn{7}{|c|}{ 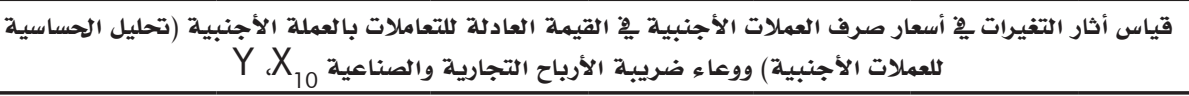 } \\
\hline None $^{*}$ & 0.086933 & 43.68736 & 12.32090 & 31.37656 & 11.22480 & .0001 \\
\hline At most $1^{*}$ & 0.035054 & 12.31080 & 4.129906 & 12.31080 & 4.129906 & .0000 \\
\hline
\end{tabular}

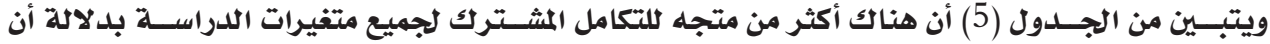

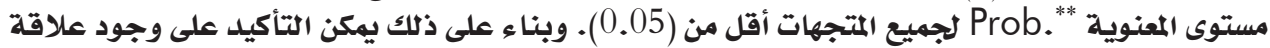

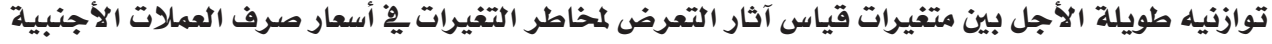

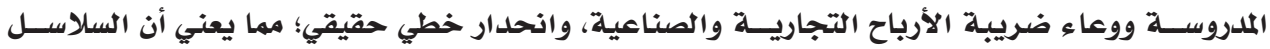

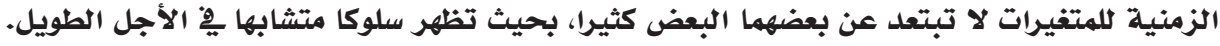




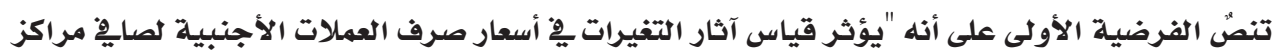

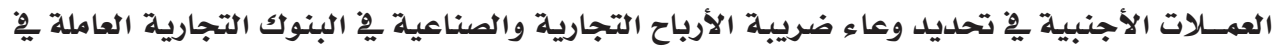

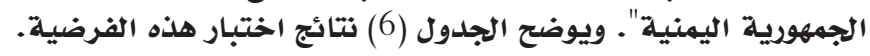

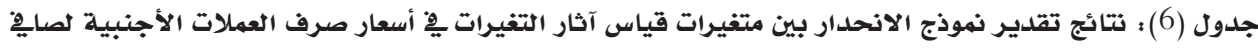
مراكز العملات الأجنبية ووعاء ضريبة الأرباح التجارية والصناعية التبارية

\section{Dependent Variable: Y Method: Least Squares}

Sample 1385, Included Observations :385

\begin{tabular}{ccccc}
\hline Variable & Coefficient & Std. Error & t-Statistic & Prob. \\
\hline$X_{1}$ & 0.218944 & 0.011725 & 18.67251 & 0.0000 \\
$X_{3}$ & 0.220948 & 0.011245 & 19.64791 & 0.0000 \\
R-squared & 0.524821 & Mean dependent var & 67538.76 \\
Adjusted R-squared & 0.523456 & S.D. dependent var & 232178.1 \\
S.E. of regression & 160277.6 & Akaike info criterion & 26.81290 \\
Sum squared resid & $8.94 \mathrm{E}+12$ & Schwarz criterion & 26.83494 \\
Log likelihood & -4690.257 & Hannan-Quinn criter. & 26.82167 \\
Durbin-Watson stat & 1.783481 & & \\
\hline
\end{tabular}

ويظهر الجدول السابق (6) الآتي :

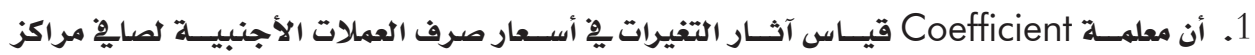

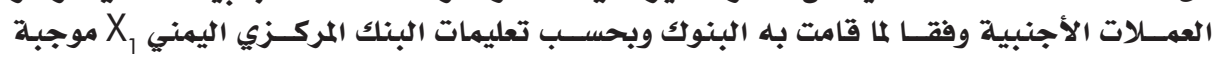
بقيمة (0.218944).

2. أن معلمة Coefficient قياس آثار التغيرات بِّ أسعار صرف العملات الأجنبية لصابِ مراكز العملات

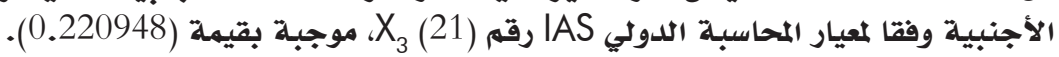

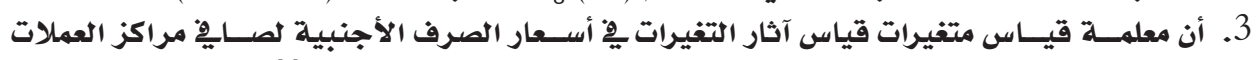

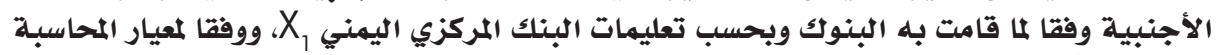

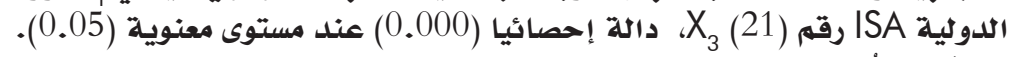

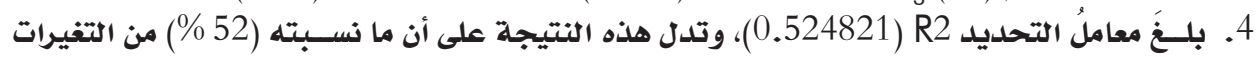

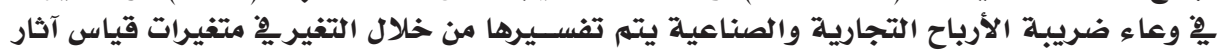

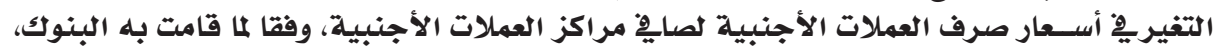

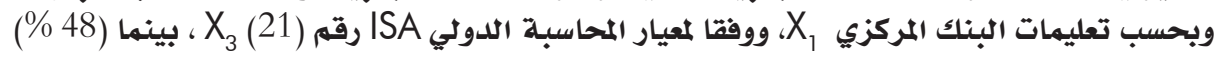

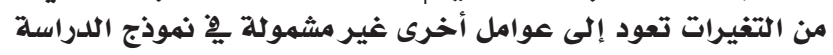

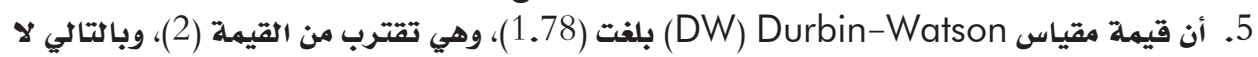
6عاني النموذج من مشكلة الارتباط الذاتئ

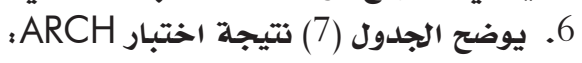


أ.د. محمد علي الربيدي أ. أشرف عبد الكريم الرصّاص الجراص

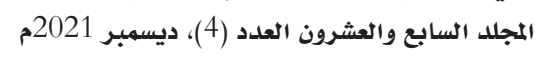

جلدول (7) : اختبار تجانس التباين لمتفيرات قياس آثار التغيرات ِِّ أسعار صرف العملات الأجنبية لصايٌٌ مراكز

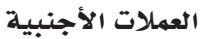

\section{Heteroskedasticity Test: ARCH}

\begin{tabular}{cccc} 
F-statistic & 0.056799 & Prob. F(1,347) & 0.8118 \\
Obs*R-squared & 0.057117 & Prob. Chi-Square(1) & 0.8111 \\
\hline
\end{tabular}

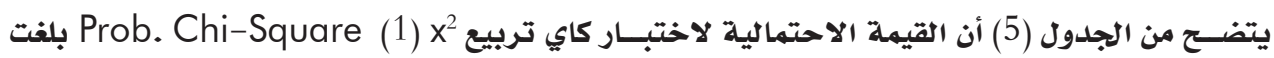

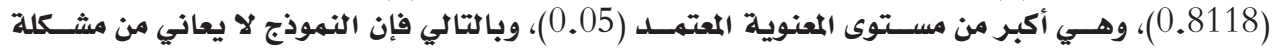

اختلاف التباين.

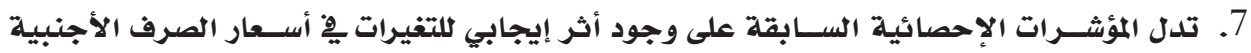

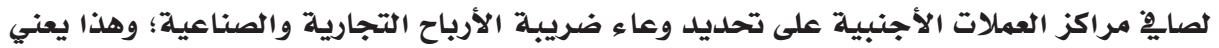

قبول الفرضية الأولى. مراكن.

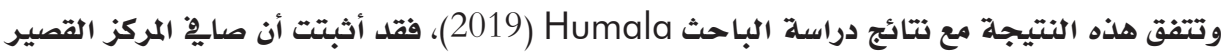

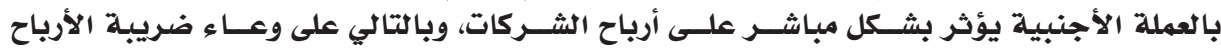

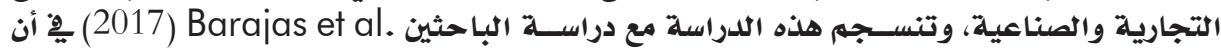

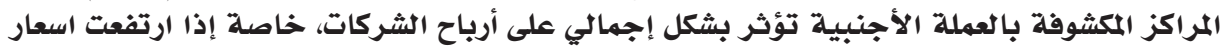

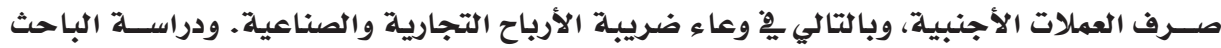
Reem

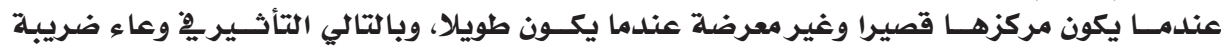

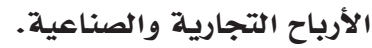

اختبار الفرضية الثانية :

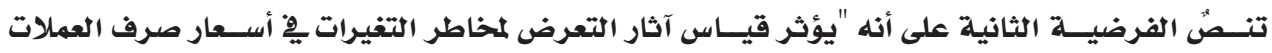

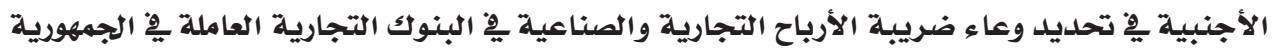
اليمنية ". ويوضح الجدول (8) نتائج اختبار هلذه الفرضيلة.

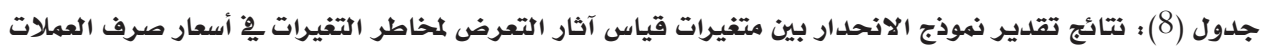

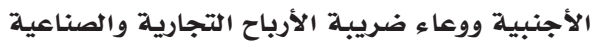

\section{Dependent Variable: Y Method: Least Squares}

Sample 1350 Included observations: 350

\begin{tabular}{ccccc}
\hline Variable & Coefficient & Std. Error & t-Statistic & Prob. \\
\hline$X_{4}$ & 0.091008 & 0.009210 & 9.881433 & 0.0000 \\
$X_{5}$ & 0.064075 & 0.028275 & 2.266140 & 0.0241 \\
$X_{6}$ & 0.159076 & 0.011295 & 14.08424 & 0.0000 \\
R-squared & 0.640068 & Mean dependent var & 67538.76 \\
Adjusted R-squared & 0.637994 & S.D. dependent var & 232178.1 \\
S.E. of regression & 139694.5 & Akaike info criterion & 26.54084 \\
Sum squared resid & $6.77 E+12$ & Schwarz criterion & 26.57391 \\
Log likelihood & -4641.647 & Hannan-Quinn criter. & 26.55400 \\
Durbin-Watson stat & 1.754970 & & \\
\hline
\end{tabular}


يظهر الجدول (8) الآتي:

1. أن معلمة Coefficient قياس آثار التعرض لمخاطر التغيرات فِ أسعار صرف العملات الأجنبية وفقا

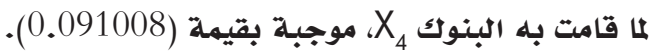

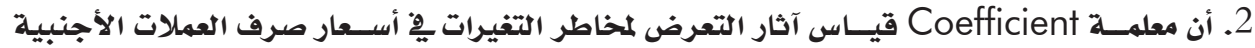

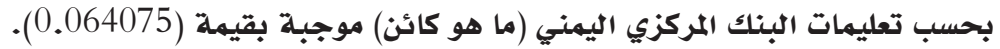

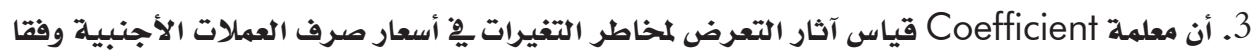

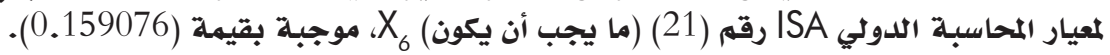

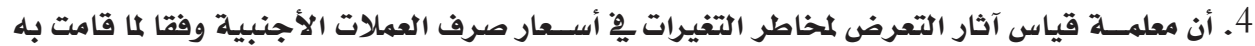

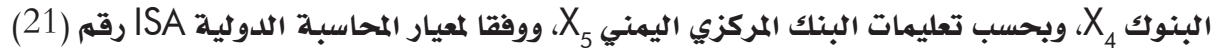

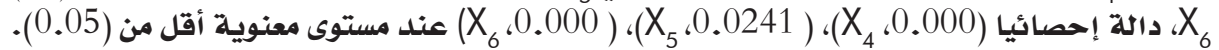

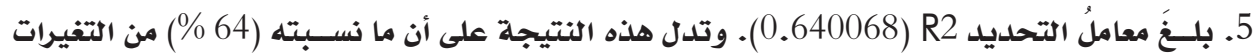

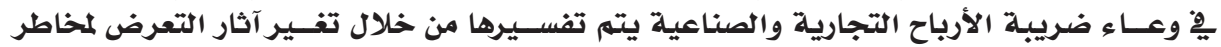

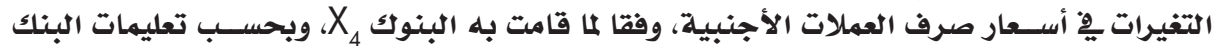

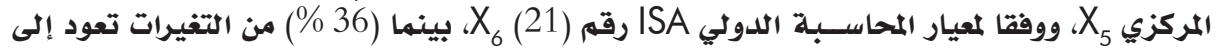

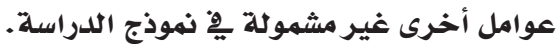

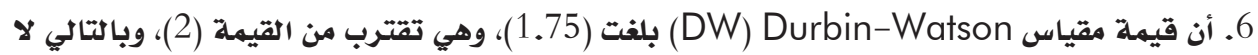
يعاني النهوذج من مشكلة الارتباط الذيات التي.

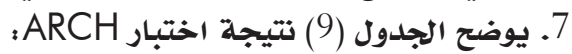

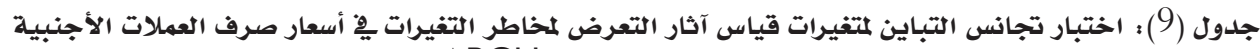
ARCH من خلال استخدام آثار التبرض اختبار

\section{Heteroskedasticity Test: ARCH}

$\begin{array}{cccc}\text { F-statistic } & 0.762542 & \text { Prob. F(1,347) } & 0.3831 \\ \text { Obs*R-squared } & 0.765255 & \text { Prob. Chi-Square(1) } & 0.3817\end{array}$

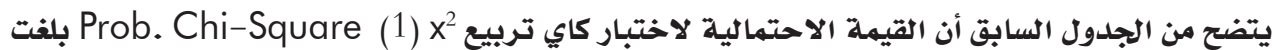

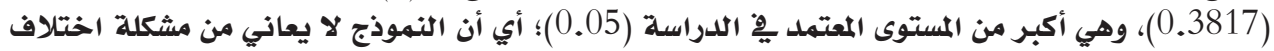
التباين.

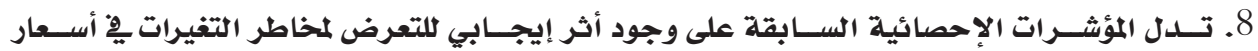

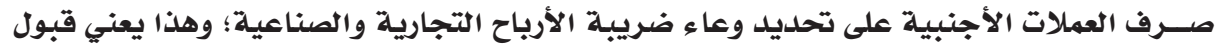
الفرضية الثانية.

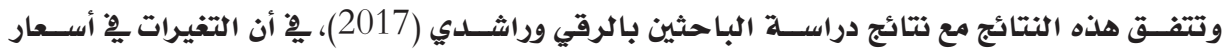

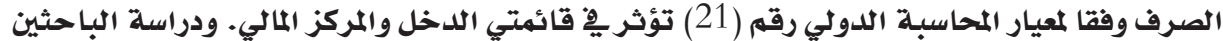
الئا Ofori et al.

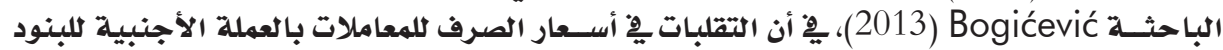
النقدية لها تأثير على أرباح الشركات. اختبار الفرضية الثالثة :

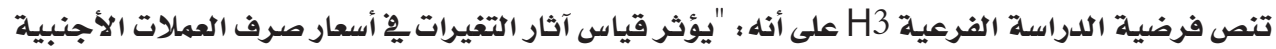

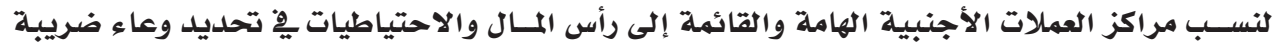

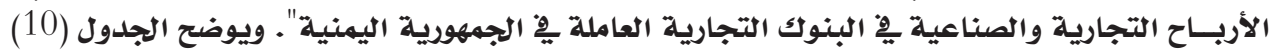
نتائج اختبار هذه الفرضية. 


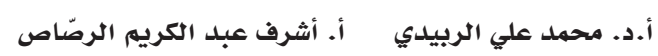

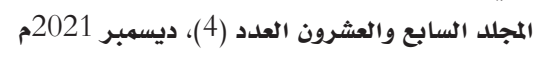

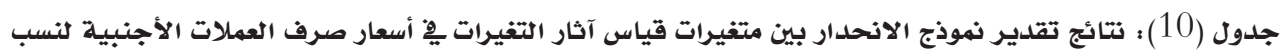

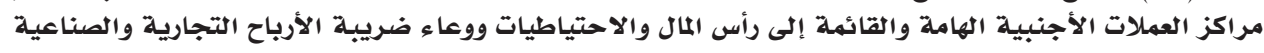

Dependent Variable: Y Method: Least Squares

Sample 1350 Included observations: 350

\begin{tabular}{ccccc}
\hline Variable & Coefficient & Std. Error & t-Statistic & Prob. \\
\hline$X_{7}$ & 0.105112 & 0.023775 & 4.421195 & 0.0000 \\
$X_{8}$ & 0.201210 & 0.029311 & 6.864704 & 0.0000 \\
$X_{9}$ & 0.356622 & 0.024812 & 14.37286 & 0.0000 \\
R-squared & 0.558798 & Mean dependent var & 0.034383 \\
Adjusted R-squared & 0.556255 & S.D. dependent var & 5.013795 \\
S.E. of regression & 3.33898 & Akaike info criterion & 5.258292 \\
Sum squared resid & 3870.758 & Schwarz criterion & 5.291360 \\
Log likelihood & -917.2021 & Hannan-Quinn criter. & 5.271455 \\
Durbin-Watson stat & 2.029484 & & \\
\hline
\end{tabular}

ويظهر الجدول (10) الآتي:

1. أن معلمة Coefficient قياس آثار التفيرات يِ أسعار صرف العملات الأجنبية لنسب مراكز العملات

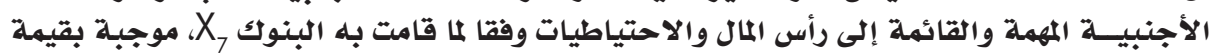
.(0.105112)

2. أن معلمة Coefficient قياس آثار التفيرات يِّ أسعار صرف العملات الأجنبية لنسب مراكز العملات

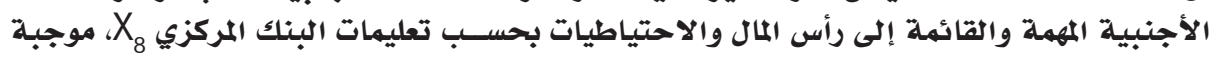
بقيمة (0.201210).

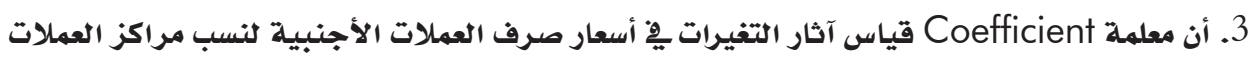

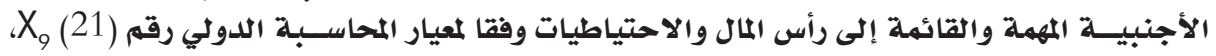
موجبة بقيمة (0.356622).

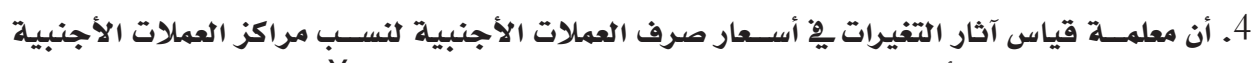

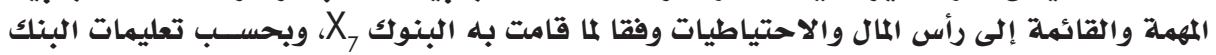

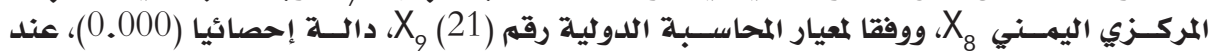
مستوى معنوية أقل من (0.05).

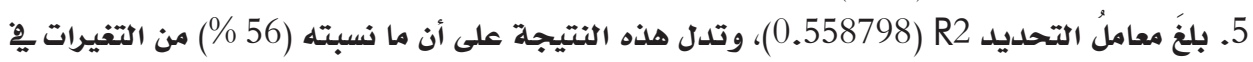

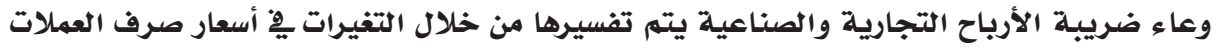

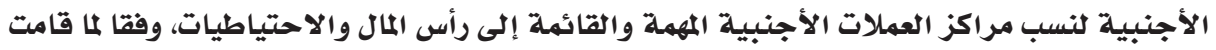

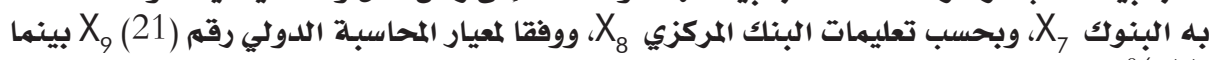
(

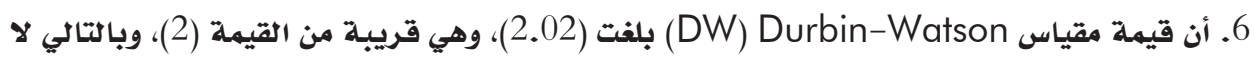
يعاني النموذج من مشكلة الارتباط الذاتي.

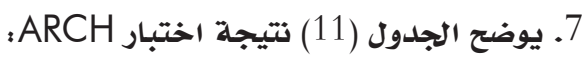




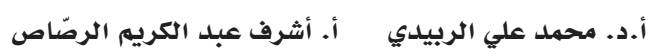

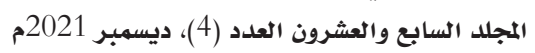

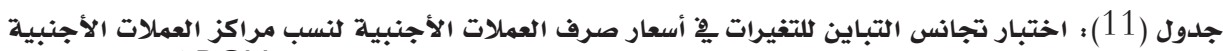

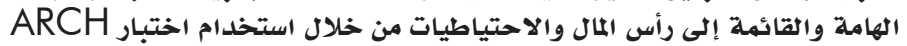

\section{Heteroskedasticity Test: ARCH}

F-statistic

Obs*R-squared
0.1446683

0.147466
Prob. F(1,347)

Prob. Chi-Square(1)
0.7020

0.7010

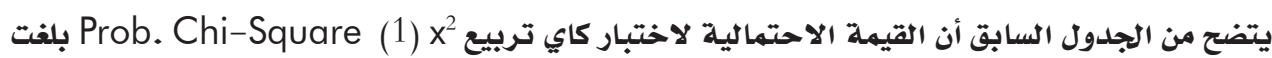

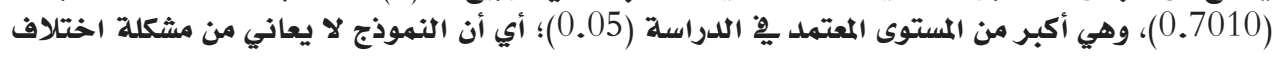
التباين.

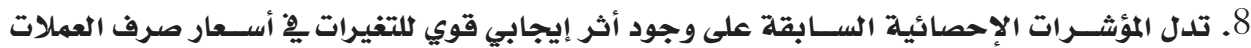

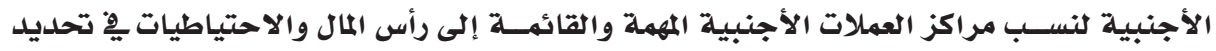

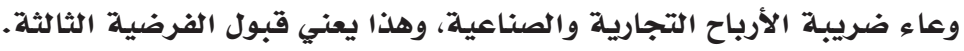

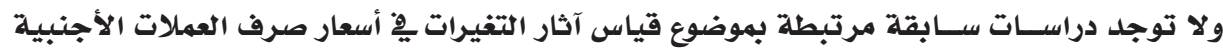

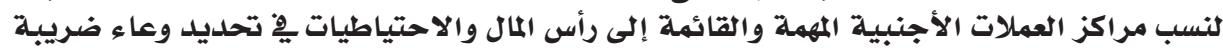

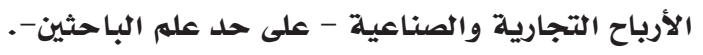

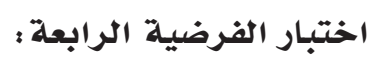

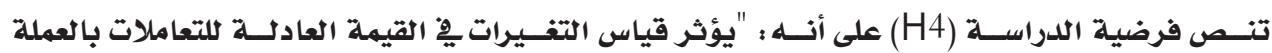

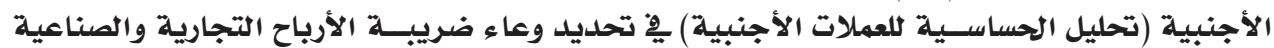

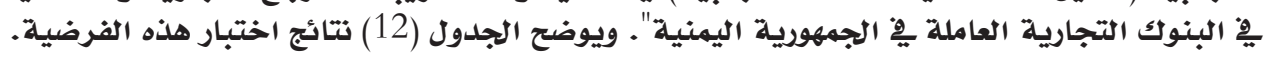

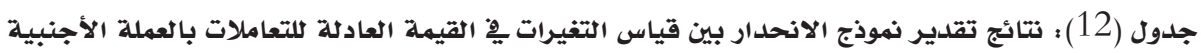

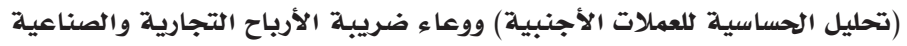

\section{Dependent Variable: Y Method: Least Squares}

Sample 1350 Included observations: 350

\begin{tabular}{ccccc}
\hline Variable & Coefficient & Std. Error & t-Statistic & Prob. \\
\hline $\mathrm{X}_{10}$ & 0.218835 & 0.013001 & 16.83200 & 0.0000 \\
R-squared & 0.401223 & Mean dependent var & 67538.76 \\
Adjusted R-squared & 0.401223 & S.D. dependent var & 232178.1 \\
S.E. of regression & 179661.0 & Akaike info criterion & 27.03838 \\
Sum squared resid & $1.13 \mathrm{E}+13$ & Schwarz criterion & 27.04941 \\
Log likelihood & -4730.717 & Hannan-Quinn criter. & 27.04277 \\
Durbin-Watson stat & 1.855581 & & \\
\hline
\end{tabular}

يتبن من الجدول (12) الآتي:

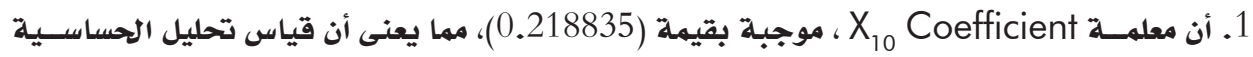

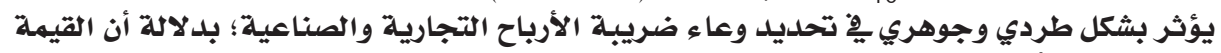

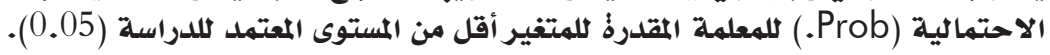

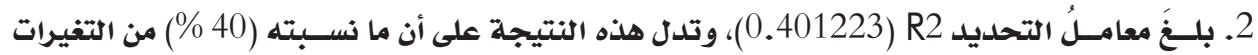

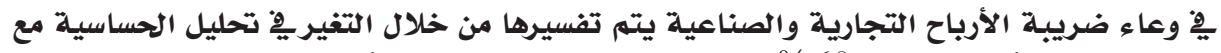

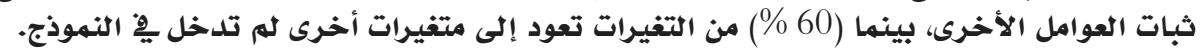




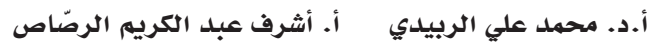

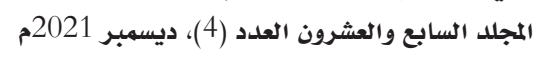

3. أن قيمة مقياس DW) Durbin-Watson) بلغت (1.86)، وهي تقترب من القيمة (2)، وبالتالي لا يعاني النهوذج من مشكلة الارتباط الذاتي.

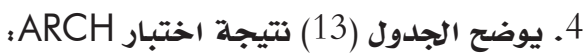

جدول (13): اختبار تجانس التباين لتحليل الحساسية

\section{Heteroskedasticity Test: ARCH}

F-statistic

Obs*R-squared

0.755406

0.758110

Prob. $F(1,347)$

0.3854

Prob. Chi-Square(1)

0.3839

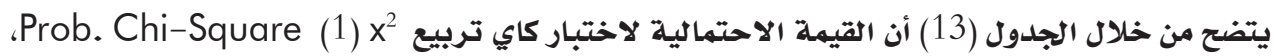

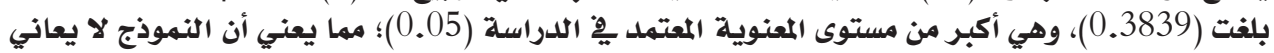
من مشكلة اختتلاف التباين.

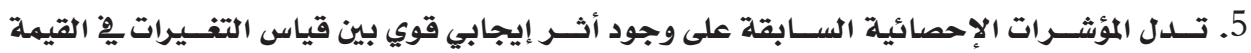

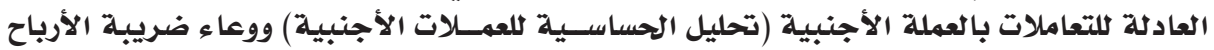

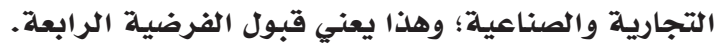

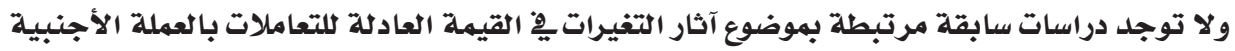

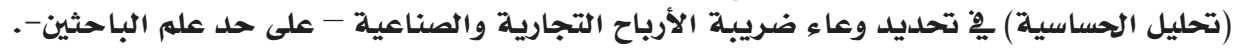

الاستنتاجات:

مِِّ ضوء تلك النتائج تم التوصل إلى عدةُ استنتاجات، أهمها : ه أن بيانات السلاسل الزمنية لفترةٌ الدراسة (2011م- 2017م) للقوائم المالية المنشورة للبنوك التجارية العاملة فِِ الجمهورية اليمنية مستقرة.

ه توجد علاقة توازنية بين متغيرات قياس آثار التغيرات يفّ أسعار الصرف ووعاء ضريبة الأرباح التجارية والصناعية، وأن الانحدار الخطي حقيقي.

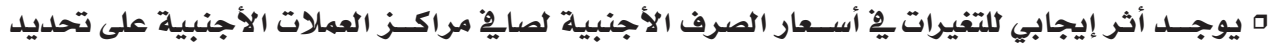
وعاء ضريبة الأرباح التجارية والصناعية التيراتية.

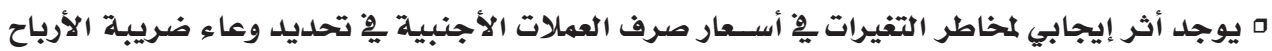
التجارية والصناعية.

ه يوجد أثر إيجابي للتفيرات فِ أسـعار الصرف الأجنبية لنسـب مراكز العملات الأجنبية إلى رأس المال

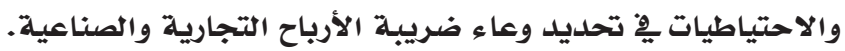

ه يوجد أثر إيجابي بين قياس التغيرات فِّ القيمة العادلة للتعاملات بالعملة الأجنبية (تحليل الحساسية الإسية للعملات الأجنبية) ووعاء ضريبة الأرباح التبين التجارية التيرات والصناعية. التوصيات:

مِّف ضوء الاستنتاجات تم التوصل إلى عدةٌ توصيات أهمها ؛

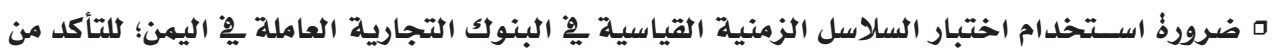
استقرار السلاسل الزمنية.

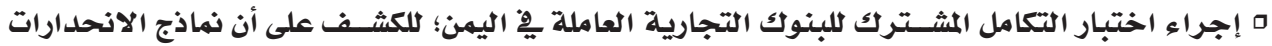
حقيقية وليست نماذج مزيفة. 


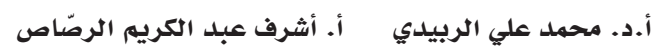

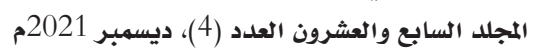

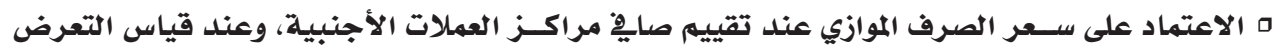

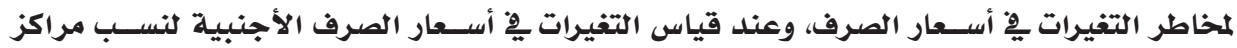

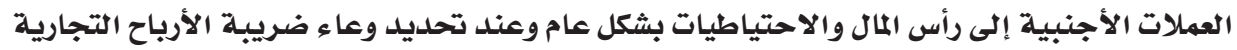
والصناعية بشكل خاص.

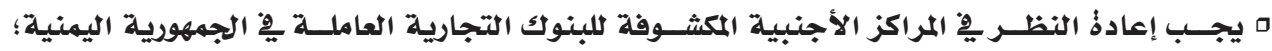
لتحقيق التوازن بين الأصول والالتزامات من العملات الأجنبية.

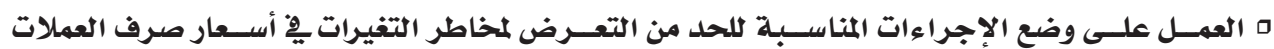
الأجنبية العمل

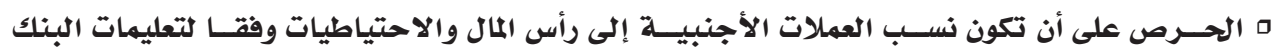

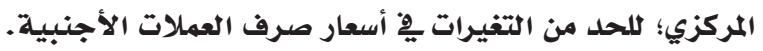
الالسهام البحثي:

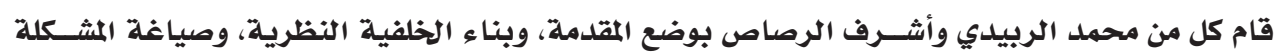

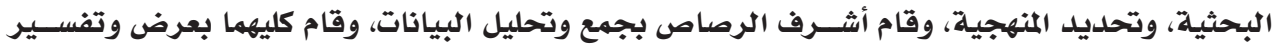

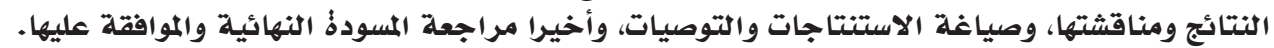

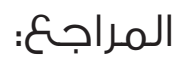

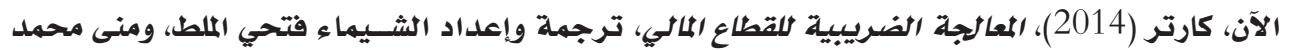

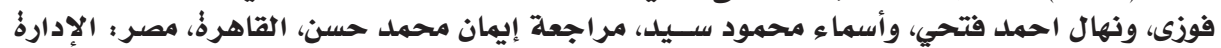

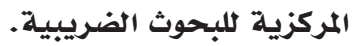

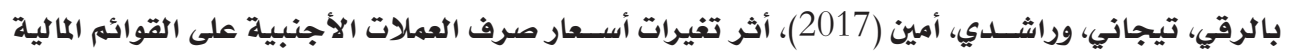

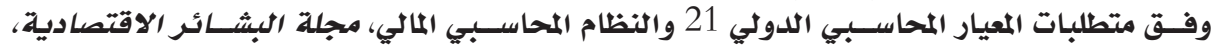

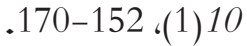

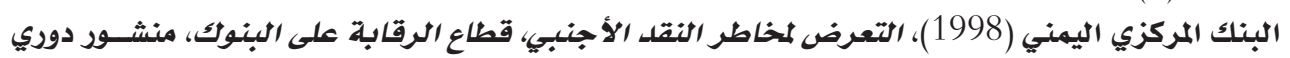

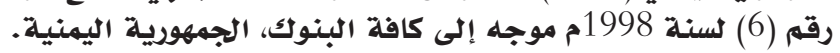

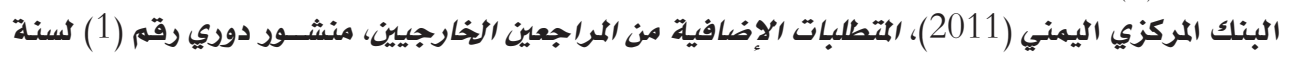

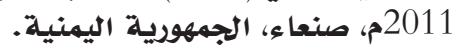

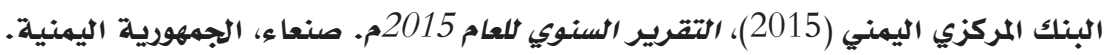

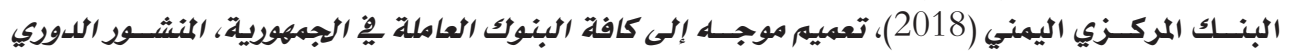

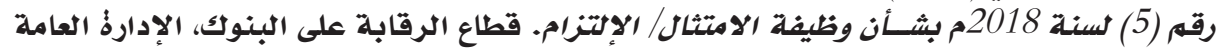

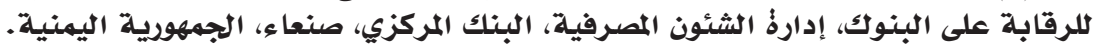

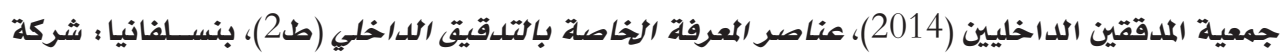
.PRC جيجــاراتي، دامــودار (2015)، الاقتصاد القياســي، ترجمة ومراجعة هند عبدار الغفــار عودةٌ وعفاف علي حسين الدش، الرياض داض : دار المريخ للنشر.

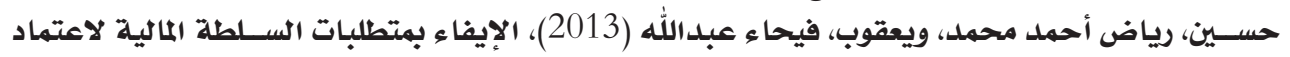

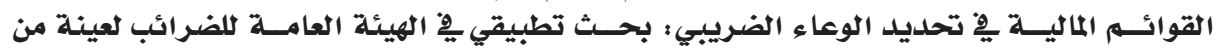

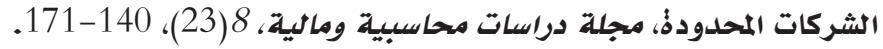

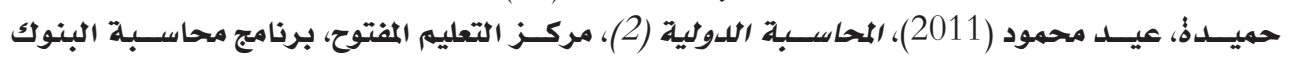
والبورصات، كلية التجارةٌ، جامعة معدة بنها. 


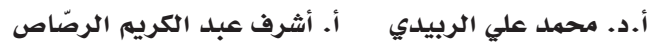

المجلد السابع والعشرون العدد (4)، ديسمبر ألرفيل الكريم المرصاصي 2021م

الربيدي، محمد علي، والحاج، محمد سـعيد (2014)، المحاسـبة الضربيبية وفقا وأحكام القانون رقهم (17)

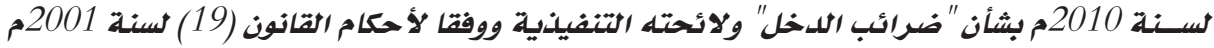

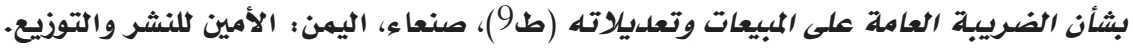

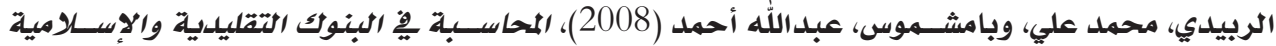

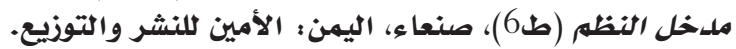

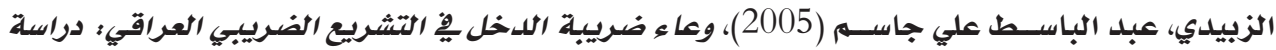
مقارنة (أطروحة دكتوراه)، جامعة الموصل، المباس، العراق.

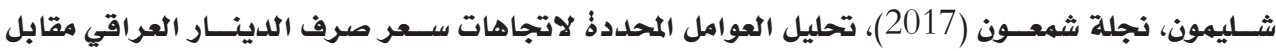

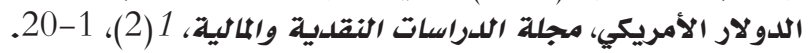

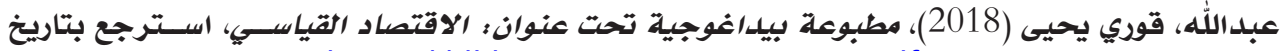

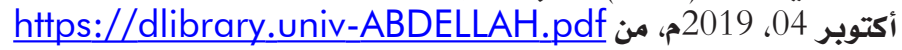

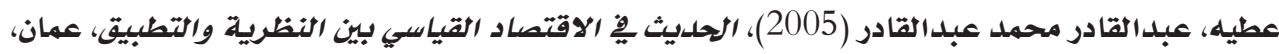

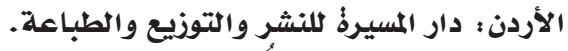

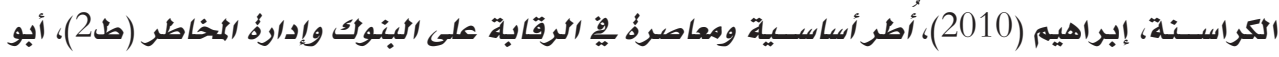
ظبي : معهد السياسات الاقتصاديسادية.

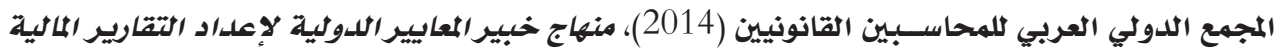

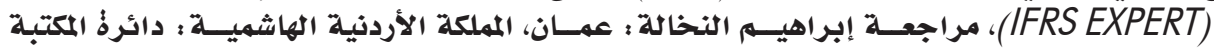
الوطنية.

المركز الوطني للمعلومات (2019)، نبذةُ تعريضية عن البنوك فِ اليهن، استرجع بتاريخ مارس 25، 2020م،

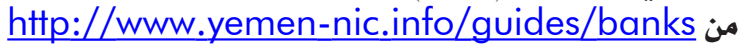

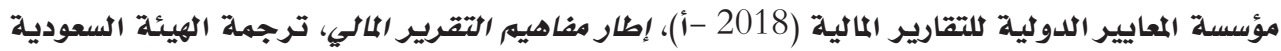

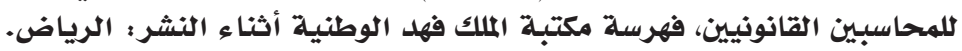

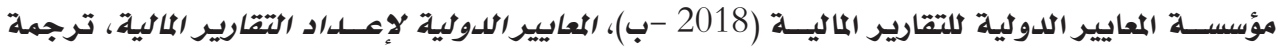

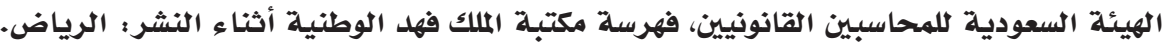

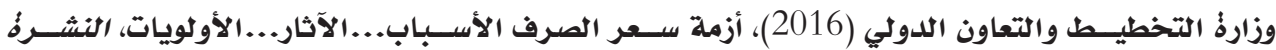

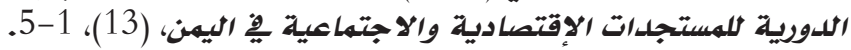

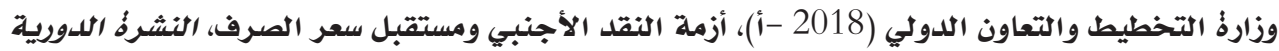

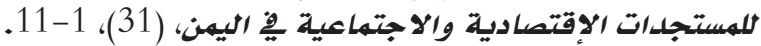

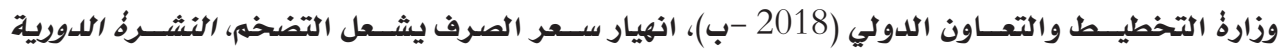

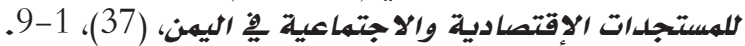

Altunok, F., Aytug, H., \& Oduncu, A. (2014). Understanding exchange rate exposure through net foreign exchange position channel. Retrieved from https://bit.ly/3mAXzoH

Barajas, M. A., Restrepo, S., Steiner, M. R., Medellín, J. C., \& Pabón, C. (2017). Currency mismatches and vulnerability to exchange rate shocks: Nonfinancial firms in Colombia. IMF Working Paper No. 17/263. International Monetary Fund. Bretton Woods, New Hampshire.

Bogićević, J. (2013). Accounting implications of foreign currency transactions translation and hedging. Ekonomski Horizonti, 15(2), 133-148. 


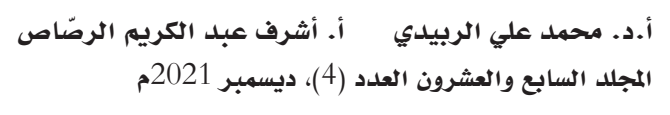

Bogićević, J., Dmitrović-Šaponja, L., \& Pantelić, M. (2016). Foreign exchange transaction exposure of enterprises in Serbia. Economic Annals, 67(209), $161-177$.

Deloitte (2018). A roadmap to foreign currency transactions and translations. Retrieved from https://bit.ly/3qlOKuf

Fabac, R., Calopa, M. K., Hrustek, N. Z., \& Kocijan, K. (2015). Risk management in the banking sector: Observations on Basel li implementation in Croatia. In the $9^{\text {th }}$ International Scientific Conference about Economic and Social Development, 9-10 April, Varazdin Development and Entrepreneurship Agency (VADEA), Istanbul.

Humala, A. (2019). Corporate earnings sensitivity to FX volatility and currency exposure: evidence from Peru. Working Papers 2019-021, Banco Central de Reserva del Perú, South America.

Juhandi, N., \& Fahlevi, M. (2019). Tax policy and fiscal consolidation on corporate income tax. Journal of Business, Management, \& Accounting, 1(1), 21-33.

Mbithi, A. M. (2009). The effect of foreign exchange rates on the financial performance of firms listed at the Nairobi securities exchange (Master Thesis). University of Nairobi, Nairobi.

McDonald, J. D., Kawaller, I. G., Harter, L. G., \& Maydew, J. P. (2011). Devil is in the details: Problems, solutions and policy recommendations with respect to currency translation, transactions and hedging. Taxes, 89(3), 199-286.

Mortură, L. A., Vârteiu, D. P., \& Dreghiciu, A. E. (2017). Procedures and techniques specific to creative accounting used in registering the exchange rate differences. SEA-Practical Application of Science, (15), 407-411.

Ofori, I. K., Obeng, C. K., \& Armah, M. K. (2018). Exchange rate volatility and tax revenue: Evidence from Ghana. Cogent Economics \& Finance, 6(1), 1537822.

Papaioannou, M. M. G. (2006). Exchange rate risk measurement and management: Issues and approaches for firms. Working Paper (No. 6-255). International Monetary Fund. Bretton Woods, New Hampshire.

Reem, J. (2004). The exchange rate exposure of banking institutions (Doctoral dissertation). University of Nebraska, Lincoln, Nebraska.

Sanaullah, Ali, S., Farmanullah, \& Furhanullah (2017). The impact of income tax and inflation on salary: A case study of government Gazetted teachers in Peshawar, Pakistan. Journal of Business Studies Quarterly, 8(4), 48-60.

Sekaran, U., \& Bougie, R. (2010). Research methods for business: A skill building approach $\left(5^{\text {th }}\right.$ ed.). New Jersey: John Wiley \& Sons. 
أ.د. محمد علي الربيدي أ. أشرف عبد الكريم الرصّاص الرئ

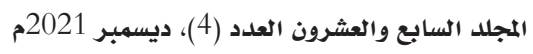

Tereščenko, D. (2014). Foreign exchange rates in consolidated financial statements under IFRS. Scientific papers of the University of Pardubice. Series D, Faculty of Economics and Administration. Retrieved from https://bit.ly/3EnbGUI

\section{Arabic References in Roman Scripts:}

Abdallah, Quri Yahya (2018). Matbueat bidaghujiat taht eunwani: Aliaqtisad alqiasii, Astarjie bitarikh Uktubar 04, 2019, min https://dlibrary.univ-ABDELLAH.pdf

Alan, Kartir (2014). Almuealajat aldaribiat lilqitae almali, Tarjamat wa'iiedad alshuyma' fathi almulata, wa Muna Muhamad Fawzi, wa Nahal Ahmad Fatahi, wa Asma' Mahmud Sayid, Murajaeat Eman Muhamad Hasan, Alqahirat, Misr: Al'iidarat Almarkaziat Lilbuhuth Aldaribiiti.

Albank Almarkaziu Alyamaniu (1998). Altaearud limakhatir alnaqd al'ajnabi, Qitae Alraqabat Alaa Albunuki, Manshur dawriin raqm (6) lisanat 1998 muajah 'iilaa kafat albunuka, Aljumhuriat Alyamaniati.

Albank Almarkaziu Alyamaniu (2011). Almutatalabat al'iidafiat min almurajiein alkhariiiizna, Manshur dawriin raqm (1) lisanat 2011. Sana'a, Aljumhuriat Alyamaniatu.

Albank Almarkaziu Alyamaniu (2015). Altaqrir alsanawiu lileam 2015. Sana'a, Aljumhuriat Alyamaniatu.

Albank Almarkaziu Alyamaniu (2018). Taemim muajah 'iilaa kafat albunuk aleamilat fi aljumhuriati, Almanshur aldawrii raqm (5) lisanat 2018 bishan wazifat alaimtithal/ al'iltizam. Qitae Alraqabat alaa Albunuki, Al'iidarat Aleamat Lilraqabat alaa Albunuki, 'iidarat alshuyuwn almasrifiati, Albank Almarkazi, Sana'a, Aljumhuriat Alyamania.

Alkarasina, Ibrahim (2010). Utor Asasiat wamueasirat fi alraqabat ealaa albunuk wa'iidarat almakhatir (Taba'a 2), Abu Dhabi: Maehad Alsiyasat Alaiqtisadiati.

Almajmae Alduwliu Alearabiu Lilmuhasibin Alqanuniiyn (2014). Minhai khabir almaeayir alduwliat li'iiedad altaqarir almalia (IFRS EXPERT), Murajaeat Ibrahim Alnikhalat: Amman, Al'urdun: Dayirat Almaktabat Alwataniati.

Almarkaz Alwataniu Lilmaelumat (2019). Nubdhat taerifiat ean albunuk fi alyaman, Astariie bitarikh Maris 25, 2020, min http://www.yemen-nic.info/guides/banks

Alrubaidi, Muhamad Ali, wa Alhai, Muhamad Saeid (2014). Almuhasabat aldaribiat wfaaan li'ahkam alqanun raqm (17) lisanat $2010 \mathrm{~m}$ bishan "darayib aldakhla" walayihatih altanfidhiat wwfaaan li'ahkam alqanun (19) lisanat 2001 bishan aldaribat aleamat ealaa almabieat wataedilatih (Taba'a 9), Sana'a, Alyaman: Al'amin Lilnashr Waltawziei. 


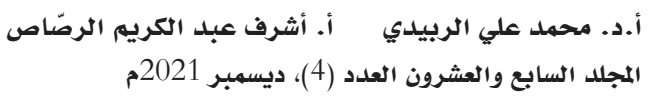

Alrubaidi, Muhamad Ali, wa Bamashmus, Abdallah Ahmad (2008). Almuhasabat fi albunuk altaqlidiat wal'iislamiat madkhal alnuzam (Taba'a 6), Sana'a, Alyaman: Al'amin Lilnashr Waltawziei.

Alzubaydi, Abdulbasit Ali Jasim (2005). Waea' daribat aldakhl fi altashrie aldaribii aleiraqii: dirasat muqarana (Utaruhat dukturah), Jamieat Almusil, Aleiraq.

Atayah, Abdalqadir Muhamad Abdalqadir (2005). Alhadith fi alaiqtisad alqiasii bayn alnazariat waltatbiqi, Amman, Al'urdun: Dar Almasirat Lilnashr Waltawzie Waltibaeati.

Balrky, Tijani, wa Rashidi, Amin (2017). Athar taghayurat 'asear sarf aleumlat al'ajnabiat ealaa alqawayim almaliat wifq mutatalibat almieyar almuhasabii alduwalii 21 walnizam almuhasabii almalii, Majalat Albashayir Alaiqtisadiati, $10(1), 152-170$.

Hamida, Eid Mahmoud (2011). Almuhasabat alduwlia (2), Markaz Altaelim Almaftuhi, Barnamai Muhasabat Albunuk wa Albursati, Kuliyat Altijarati, Jamieat Binha.

Hussein, Riyadh Ahmed Mohammed, wa Yacoub, Faiha Abdullah (2013). Al'iifa' bimutatalabat alsultat almaliat liaietimad alqawayim almaliat fi tahdid alwuea' aldaribii: Bahth tatbiqiun fi alhayyat aleamat lildarayib lieayinat min alsharikat almahdudati, Majalat Dirasat Muhasabiat Wamaliati, 8(23), 140-171.

Jameiat Almudaqiqin Aldaakhiliiyn (2014). Anasir almaerifat alkhasat bialtadqia aldaakhilii (Taba'a 2), Binsilfanya: Sharikat PRC.

Jijarati, Damudar (2015). Alaiqtisad alqiasiv, Tarjamat wa Murajaeat Hind Abdul-Ghaffar Odeh wa Afaf Ali Hussain Al-Dash, Alrayad: Dar Almiriykh Lilnashri.

Muasasat Almaeayir Alduwliat Liltaqarir Almalia (2018a). Itar mafahim altaqrir almaliv, Tariamat Alhayyat Alsaeudiat Lilmuhasibin Alqanuniiyna, Fahrasat Maktabat Almalik Fahd Alwataniat Aithna' Alnashri: Alriyad.

Muasasat Almaeayir Alduwliat Liltaqarir Almalia (2018b). Almaeayir alduwliat li'iiedad altaqarir almaliati, Tarjamat Alhayyat Alsaeudiat Lilmuhasibin Alqanuniiyna, Fahrasat Maktabat Almalik Fahd Alwataniat Aithna' Alnashri: Alriyad.

Shalimun, Nailat Shameun (2017). Tahlil aleawamil almuhadadat liaitijahat sier sarf aldiynar Aleiraqii muqabil alduwlar Al'amrikii, Majalat Aldirasat Alnaqdiat Walmaliati, 1(2), 1-20.

Wizarat Altakhtit Waltaeawun Alduwalii (2016). Azmat sier alsarf al'asbaba... alathar...al'awlawiaati, Alnashrat Aldawriat Lilmustajadaat Al'iiqtisadiat Walaijtimaeiat fi Alyaman, (13), 1-5. 


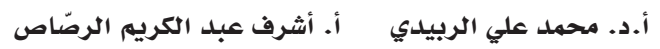

المجلد السابع والعشرون العدد (4)، ديسمبر 2021م أرفيل الكريب الرصاصي

Wizarat Altakhtit Waltaeawun Alduwalii (2018a). Azmat alnaqd al'ajnabii wamustaqbal sier alsaraf, Alnashrat Aldawriat Lilmustajadaat Al'iiqtisadiat Walaijtimaeiat fi Alyaman, (31), 1-11.

Wizarat Altakhtit Waltaeawun Alduwalii (2018b). Ainhiar sier alsarf yusheil altadakhumu, AlnashratAldawriat LilmustajadaatAl'iiqtisadiat Walaijtimaeiat fi Alyaman, (37), 1-9. 